\title{
Metabolic syndrome, dyslipidemia, hypertension and type 2 diabetes in youth: from diagnosis to treatment
}

\author{
Alfredo Halpern ${ }^{1}$, Marcio C Mancini ${ }^{1 *}$, Maria Eliane C Magalhães ${ }^{2}$, Mauro Fisberg ${ }^{3}$, Rosana Radominski ${ }^{4}$, \\ Marcelo C Bertolami ${ }^{5}$, Adriana Bertolami ${ }^{7}$, Maria Edna de Melo ${ }^{1}$, Maria Teresa Zanella ${ }^{6}$, Marcia S Queiroz ${ }^{7}$, Marcia Nery ${ }^{7}$
}

\begin{abstract}
Overweight and obesity in youth is a worldwide public health problem. Overweight and obesity in childhood and adolescents have a substantial effect upon many systems, resulting in clinical conditions such as metabolic syndrome, early atherosclerosis, dyslipidemia, hypertension and type 2 diabetes (T2D). Obesity and the type of body fat distribution are still the core aspects of insulin resistance and seem to be the physiopathologic links common to metabolic syndrome, cardiovascular disease and T2D. The earlier the appearance of the clustering of risk factors and the higher the time of exposure, the greater will be the chance of developing coronary disease with a more severe endpoint. The age when the event may occur seems to be related to the presence and aggregation of risk factors throughout life.

The treatment in this age-group is non pharmacological and aims at promoting changes in lifestyle. However, pharmacological treatments are indicated in special situations.

The major goals in dietary treatments are not only limited to weight loss, but also to an improvement in the quality of life. Modification of risk factors associated to comorbidities, personal satisfaction of the child or adolescent and trying to establish healthy life habits from an early age are also important. There is a continuous debate on the best possible exercise to do, for children or adolescents, in order to lose weight. The prescription of physical activity to children and adolescents requires extensive integrated work among multidisciplinary teams, patients and their families, in order to reach therapeutic success.

The most important conclusion drawn from this symposium was that if the growing prevalence of overweight and obesity continues at this pace, the result will be a population of children and adolescents with metabolic syndrome. This would lead to high mortality rates in young adults, changing the current increasing trend of worldwide longevity. Government actions and a better understanding of the causes of this problem must be implemented worldwide, by aiming at the prevention of obesity in children and adolescents.
\end{abstract}

\section{Introduction}

The worldwide concept of metabolic syndrome in children and adolescents is still a matter of discussion mainly because studies on this age group are scarce. In this Symposium of Metabolic Syndrome, Dyslipidemia, Hypertension and type 2 Diabetes in Children and Adolescents, organized by the Department of Metabolic

\footnotetext{
* Correspondence: mmancini@usp.br

${ }^{1}$ Group of Obesity and Metabolic Syndrome, Endocrinology and Metabolism Service, Hospital das Clínicas da Faculdade de Medicina, São Paulo University (HC-FMUSP). Av. Dr. Enéas de Carvalho Aguiar, 155 - $8^{\circ}$ andar - bloco 3. São Paulo, Brazil

Full list of author information is available at the end of the article
}

Syndrome of the Brazilian Society of Diabetes, many aspects of those clinical conditions were widely discussed, covering diagnosis, early atherosclerotic lesions, therapeutic management and non-pharmacological as well pharmacological treatment. The increased risk of development of comorbidities like dyslipidemia, arterial hypertension and glucose intolerance were also discussed and the following question was pointed out for the therapeutic management of each condition: When should we treat these youngsters pharmacologically?

More than 150 health care professionals including physicians, nurses and dietitians attended this Symposium 
which took place in São Paulo, providing a forum for debate on this important issue.

\section{Metabolic Syndrome Diagnosis in Children and Adolescents}

Several large epidemiology cohort studies have documented that obesity and metabolic syndrome are associated with cardiovascular outcomes in adults, such as myocardial infarction, cerebrovascular disease and sudden death [1]. In recent years, there has been a greater concern about the presence of obesity and metabolic syndrome in children and adolescents [2]. Upper Obesity is the core aspect of insulin resistance and seems to be the physiopathologic link common to metabolic syndrome.

There is no consensus regarding the diagnosis of metabolic syndrome in children and adolescents as recently discussed by Mancini [3]. It is evident that each component of the syndrome must be identified as early as possible in order to prevent definitive lesions. The question is how to do this and which cut-offs must be adopted for this diagnosis.

The diagnosis of metabolic syndrome in children and adolescents requires the assessment of the abdominal circumference (or BMI), blood pressure, lipoproteins and glycemia. While the value of waist circumference as a measure of visceral adiposity remains somewhat debated, an accepted measurement of waist circumference by percentiles was established [4]. Nevertheless, there is some controversy about how to measure the abdominal circumference in children and adolescents. There are some proposals: one of which was published in 1999 by Freedman - one of the authors of the Bogalusa study [4]. In this study the authors correlated the $90^{\text {th }}$ percentile of abdominal circumference with increased levels of LDL cholesterol, glycemia, insulin and diminished HDL levels. Limits were established and the use of a table for abdominal circumference was proposed (above the $90^{\text {th }}$ percentile, considered to be the maximum normal limit).

Some people claim that metabolic syndrome in children must be defined by BMI and not by circumference. An adjusted BMI curve according to gender and age was proposed to the Brazilian population, produced by the group supervised by Monteiro \& Conde from the School of Public Health of the University of Sao Paulo [5]. Despite the existence of this curve, even for the matter of comparing studies, BMI curves adjusted by the North-American CDC have been more widely used [6]. Normal BMI varies according to the child's age. Thus, it is impossible to apply a BMI range of 18.5-24.9 to a 12 or 13-year-old child. Overweight is defined as above the $85^{\text {th }}$ percentile and obesity above the $95^{\text {th }}$ percentile (tables available at http://www.cdc.gov).
Nonetheless, with the launching of the WHO references for children 5-19 years old, obesity is considered as above the $97^{\text {th }}$ percentile or $2^{\text {nd }} \mathrm{SD}$ or $\mathrm{z}$ score (available at http://www.who.int/growthref).

\section{Proposals for the Definition of Metabolic Syndrome in Children and Adolescents}

For a discussion about the various proposals for the definition of metabolic syndrome in children, refer to reference 3.

The definition considered most appropriate and which was added to this SBD publication is the one proposed by the IDF. It divided children into age groups. There was not a well defined proposal for children under 6 years of age, due to the lack of data. Unlike the criteria presented above, for a matter of convenience, the cut-offs in this proposal were fixed for pressure, lipids and glucose, and abdominal circumference points were assessed by percentile. In children aged 6-10, the cutoffs for metabolic and blood pressure variables were not well defined, therefore, only adiposity levels were evaluated (considering abdominal circumference above the $90^{\text {th }}$ percentile). The same criteria would be used for children aged 10-16; regarding glucose and lipid metabolism, fasting glucose levels $\geq 100 \mathrm{mg} / \mathrm{dl}$, triglycerides $\geq 150 \mathrm{mg} / \mathrm{dl}$, HDL cholesterol below $40 \mathrm{mg} / \mathrm{dl}$ or the use lipid lowering drugs were considered risk factors as well blood pressure $\geq 130$ or $\geq 85 \mathrm{mmHg}$. If the patient has abnormal abdominal circumference and two more factors, the metabolic syndrome diagnosis is established. The difference is that, for adolescents over 16 years of age, there is a distincition between HDL $\leq 40$ for men or $\leq 50$ for women, as described in Table 1 .

The IDF criteria, though more convenient, fail to include some children in the diagnosis of Metabolic Syndrome. On the other hand, it would be easier to accept as it does not use multiple tables to assess several anthropometric and metabolic criteria [7].

\section{Atherosclerosis in Young Adults}

The acknowledgement of the presence of atherosclerotic disease in young adults was demonstrated in necropsy studies of American soldiers who were victims of the Vietnam War. The lesions found in these individuals varied from the presence of foam cells and fatty stretch marks to type 4 lesions, i.e., mature atherosclerotic plaques, with a well developed lipid core and the presence of cholesterol and inflammatory cell crystals [8]. Based on these findings and on the findings of other studies, it was possible to certify that young individuals may already present advanced atherosclerotic lesions. Studies then continued to even lower age ranges, such as children and adolescents, where atherosclerotic evidence was also demonstrated. In this scenario, the Bogalusa 
Table 1 Classification of metabolic syndrome in children and adolescents [3]

\begin{tabular}{|c|c|c|c|}
\hline \multirow{2}{*}{$\begin{array}{l}\text { Criteria/ } \\
\text { components }\end{array}$} & \multicolumn{3}{|c|}{ Age } \\
\hline & 6 to $<10$ years-old & 10 to 16 years-old & $>16$ years-old \\
\hline $\begin{array}{l}\text { Adiposity } \\
\text { definition }\end{array}$ & $W C \geq 90^{\text {th }}$ percentile & $W C \geq 90^{\text {th }}$ percentile & $W C \geq 90 \mathrm{~cm}$ (boys) or $\geq 80 \mathrm{~cm}$ (girls) \\
\hline $\begin{array}{l}\text { Glucose } \\
\text { metabolism }\end{array}$ & $\begin{array}{l}\text { Without cut-off definition for } \\
\text { MS diagnosis }\end{array}$ & Fasting blood glucose $\geq 100 \mathrm{mg} / \mathrm{dl}$ & Fasting blood glucose $\geq 100 \mathrm{mg} / \mathrm{dl}$ \\
\hline Dyslipidemia & $\begin{array}{l}\text { Without cut-off definition for } \\
\text { MS diagnosis }\end{array}$ & $\begin{array}{l}\mathrm{Tg} \geq 150 \mathrm{mg} / \mathrm{dl} \text { or } \mathrm{HDL}-\mathrm{ch} \geq 40 \mathrm{mg} / \mathrm{dl} \\
\text { or taking LLD }\end{array}$ & $\begin{array}{l}\mathrm{Tg} \geq 150 \mathrm{mg} / \mathrm{dl} \text { or } \mathrm{HDL} \text {-ch } \geq 40 \text { (boys) or } \geq 50 \mathrm{mg} / \mathrm{dl} \\
\text { (girls) or taking LLD }\end{array}$ \\
\hline $\begin{array}{l}\text { Arterial } \\
\text { hypertension }\end{array}$ & $\begin{array}{l}\text { Without cut-off definition for } \\
\text { MS diagnosis }\end{array}$ & $\begin{array}{l}\mathrm{DBP} \geq 130 \text { or } \mathrm{SBP} \geq 85 \mathrm{mmHg} \text { or taking } \\
\mathrm{AHD}\end{array}$ & $\mathrm{DBP} \geq 130$ or $\mathrm{SBP} \geq 85 \mathrm{mmHg}$ or taking $\mathrm{AHD}$ \\
\hline
\end{tabular}

WC: waist circumference; MS: metabolic syndrome; Tg: triglyceride levels; HDL-ch: HDL-cholesterol levels; LLD: lipid-lowering drug; DBP: diastolic blood pressure; SBP: systolic blood pressure; AHD: antihypertensive drug.

Study stands out: approximately 12,000 children and adolescents were prospectively and longitudinally followed up. The authors analyzed the prevalence of the main cardiovascular risk factors (RF) and observed that they recurred throughout life, in a phenomenon known as "tracking", i.e., if they were present during early age, they were more likely to persist throughout life [9]. About 190 of these individuals died from different causes and were submitted to necropsy, and the presence of fibrous plaques in the aorta and coronary arteries was described, confirming that atherosclerosis was present since a very early age. Researchers also found that lesions were increasingly severe according to more advanced age and in the presence and/or aggregation of cardiovascular risk factors. Among present risk factors in this cohort, obesity and systolic (but not diastolic) blood pressure stood out, either alone or combined, as the most correlated factors to the presence of aortic and coronary atherosclerotic lesions. The majority of complex lesions were associated with total cholesterol levels, LDL levels and less intensely with triglyceride levels. Smoking was also an important determining factor of early and accelerated development of atherosclerotic disease in these individuals [10]. Another study, also conducted with children and adolescents, the Pathobiological Determinants of Atherosclerosis in Youth (PDAY) also demonstrated that the aggregation of cardiovascular risk factors increased the risk of developing atherosclerotic disease, detected on the intimal vessel surface during necropsy studies [11].

These findings motivated researchers to conduct longitudinal studies on children and adolescents in an attempt to detect the prevalence of the different cardiovascular risk factors. Among these, the Estudo do Rio de Janeiro has been following up a cohort of over 3000 students of both genders, aged 6-15, for over 17 years, aiming at building blood pressure (BP) normality curves for such individuals. The prevalence of the different cardiovascular risk factors was analyzed in a subgroup made up of 365 children and adolescents and it was found to be $14.6 \%$ for arterial hypertension, $21.6 \%$ for overweight and/or obesity, $39.6 \%$ for dyslipidemia and $14.8 \%$ for smoking [12]. Similar studies conducted in the USA reported prevalence percentiles of 5-20\% for hypertension, 20-33\% for overweight/obesity, 13-35\% for dyslipidemia and $25-35 \%$ for smoking [13]. Remarkably, such prevalence is very similar to that found in adults.

The continuum concept presented by Dzau et al. advocates that cardiovascular disease seems to develop slowly from early stages until the clinical outcome, which is frequently lethal. The earlier the appearance of cardiovascular risk factors and the greater the time of exposure, the higher the chance of developing the disease and the more severe the final endpoint is. The age at which the event may occur seems to be related to the presence and aggregation of cardiovascular risk factors in the course of life [14].

The aggregation of several cardiovascular risk factors in the same individual has been exhaustively demonstrated in all age ranges. Miura et al. showed the association between blood pressure and mortality from atherosclerotic disease in young adults in a 30 -year follow up study. The authors observed that, for each $10 \mathrm{mmHg}$ increase in systolic blood pressure, there was a $1.5 \%$ increase in mortality [15]. More recently, McCarron et al. demonstrated that cardiovascular risk doubled for each $20-\mathrm{mmHg}$ increase in systolic blood pressure and for each 10-mmHg in diastolic blood pressure [16].

Once the problem is identified, the crucial concern is about which procedure needs to be adopted with a child who has cardiovascular risk factors There are still few intervention studies about this age range and the general recommendation is to intensify efforts in order to correct risk factors and/or the presence of comorbidities with non-pharmacological measures. There is no long term study which confirms the safety of prolonged drug use, in this age range, for the treatment of hypertension, dyslipidemia, obesity and diabetes among others. However, considering the individual risk of children, pharmacological treatment has been frequently recommended 
in special situations which will be discussed later in this symposium.

\section{Nutritional Guidance for Children and Adolescents with Metabolic Syndrome}

The increasing prevalence of overweight and obesity in youngsters has also been observed in Brazil. A recent National study, the Nutri Brasil Infância, conducted with 12 universities in the country showed that over $23 \%$ of Brazilian children present excess weight up to the age of five - a fact that previously would have only be seen in later age groups $[17,18]$. We have observed an important increase in sedentary lifestyle and low physical activity levels in adolescents attending both public and private schools. It is important to emphasize that Brazilian children in general do not reach $30 \%$ of the amount of moderate physical activity time per week suggested by the World Health Organization, which would be 150 minutes [19].

Considering non-pharmacological interventions for treating children and adolescents with MS, promoting lifestyle changes, which include increasing physical activity, eating balanced diets and engaging in psychosocial approaches must be the initial step [20]. It is easier to control meals at schools than at home. The main problem regarding diet control is how to reach a healthy weight during a phase of such fast growth and gain of both fat and lean mass. The major goals in dietary treatments are not only limited to weight loss, but also to an improvement in the quality of life, with the modification of risk factors associated to comorbidities, personal satisfaction of the child or adolescent and trying to establish healthy life habits from an early age. This is not a simple task, especially when our children live among families with completely inadequate lifestyles and eating habits [21]. Some goals that are well established for adults will depend on age range, puberty stage and gender when applied to children. For example, a 5 to $10 \%$ weight reduction, which is an exceptionally important criterion of treatment success for adults, may not be adequate for a child in growth and development, especially in puberty. Regarding diets, the general goal is to promote weight loss or stabilize the rate of weight gain, reduce visceral fat, correct dyslipidemia and normalize blood pressure [22]. These diets are generally rich in fiber and low in saturated fat, cholesterol and plain sugar content. Several types of diet allow weight loss and the reduction of blood pressure levels, and consequently minimize cardiovascular events [22]. However, the major challenge is how to adjust these diets to such a young population with habits which are so difficult to change, who often follow the family's standard of inadequateness.
From a practical point of view, it is recommended that food with high energy density be avoided, which promotes the reduction of macronutrient imbalance. Some discrepant aspects have been shown recently in our field, such as avoiding milk and dairy products, recommended by some groups. This is a conduct that contradicts epidemiological evidence which relates greater calcium intake to weight loss and a lower incidence of cardiovascular events [23,24].

In 2007 [25], the American Medical Association drafted a number of new measures and attempted to resolve MS from the dietary and behavioral standpoint, by establishing four phases of treatment:

\section{Phase 1}

global orientation for the child and the family. Simple measures such as encouraging meals like breakfast and others with the family could be useful. It is suggested that meals outside of the home be limited and family meals be encouraged, in order to allow the child to reach self-regulation, moderating the use of restrictive behaviors. In this phase, the goal would be to reduce the rate of weight gain, thereby favoring growth. If the child did not evolve properly, phase 2 would be the next suitable step.

\section{Phase 2}

structured weight management programs designed by trained primary health care professionals. These groups would work with balanced diet plans, limiting high energy density foods in the diets. In this phase, the goal is to improve the structure of meals and snacks, improve structured physical activity to at least $60 \mathrm{~min}$ utes per day, and reduce daily TV, video-game or computer time to one hour or less. Data from research and opinion institutes show that the use of electronic devices by children in Brazil has reached an average of 4.8 hours per day. The family needs to be monitored in all behavioral aspects. The objective of this period is obviously to reduce the BMI (body mass index). However, a weight loss standard is still being determined: $450 \mathrm{~g}$ per month for 2 to 11 -year-olds, climbing up to almost $1 \mathrm{~kg}$ for children and adolescents above 11 years old. If no favorable result is seen at this point, the next step would be phase 3 .

\section{Phase 3}

Implementation of activities which include the monitoring of food and physical activity, as well as short-term goals for the diet, physical activity and change in behavior must be performed with the help of a multidisciplinary team of specialists in childhood obesity, professionals with experience in giving orientation about 
diet and physical activity, offering the proper psychological, educational and emotional support. For children who remain above the $95^{\text {th }}$ percentile, with comorbidities and who have not been successfully treated in the previous phases, this phase must be tried. In this phase, diet counseling is required beyond the general orientation: a more intense restriction on calorie intake is established in association with an increase in continuous physical activity. Additional strategies are established, such as the use of food replacements, very low calorie diets, and later the use of medications - leaving gastric bypass surgery as a last possible intervention. Goals for children of ages from 6 to 11, especially in overweight children, are to maintain the weight until there is a possibility of recovery, or to get BMI rate to decrease. In obese children, we should have a lower average of weight loss. In severely obese individuals, weight loss still cannot be higher than $1 \mathrm{~kg}$ per week, which is a common barrier in most phase 3 healthcare programs. However, we have to evaluate if these children who enter programs of fat use restriction, carbohydrate intake modification and most importantly, highly restrictive weigh loss counseling may present excessive weight loss in the future, which could later result in eating disorders and premature bulimia or anorexia.

In older children, an even greater caloric restriction can be seen especially for the morbidly obese, considered as those above the $99^{\text {th }}$ percentile, or in other words the third standard deviation or third $\mathrm{Z}$ score. It is important to emphasize, that for children and adolescents to reach a lifestyle change with nutritional education and physical activity; it must be an ongoing effort that should be started at an early age. We should think that, without the adoption of dietary measures and the implementation of change in the whole family's life style, the chance of reducing factors associated with metabolic syndrome in children and adolescents will be very small.

\section{Physical Activity in Children and Adolescents - A Realistic View}

The increase in sedentary life over the last few decades is closely linked to the increase in the prevalence of overweight and obesity both in adults and children [26]. A survey conducted in London $[27,28]$ has shown that people walked 63 miles less in 2003 compared to 1975 , indicating a significant reduction in energy consumption, which contributes considerably to weight gain in adults as well as in children.

Regarding TV viewing, it has already been demonstrated that watching television, regardless of age, increases BMI, mainly in the group that watched TV for over three hours a day [29]. A key concern is that, in general, watching television is associated with higher food consumption. A study conducted in Brazil has shown that, during the times of day when children watch television, advertisings are fundamentally about the group of fats, sugars and sweets; therefore, children are encouraged to ingest high calorie foods [30]. An epidemiological assessment conducted with Hispanic Americans in Houston, Texas, has shown that obese and thin children and adolescents had low physical conditioning, which was even lower in the obese and in girls [31]. Another interesting fact shown by this study was that physical activities are different among boys (more intense activities) and girls (light and moderate activities). Physical activity changes from birth up to 18 years of age, and in general, girls practice less physical activity than boys, which is probably related to worse results in terms of weight loss with physical activity in women [32].

Regarding cardiovascular risk factors related to excess weight and metabolic syndrome in children and adolescents, different studies have shown that, at any age, the number of risk factors is inversely related to physical activity and to physical conditioning [33,34].

A meta-analysis was conducted with a systematic review of over 600 studies: out of the 14 selected with supervised exercises, four compared aerobic activity to controls, nine compared the effects of diet therapy and behavior therapy with and without aerobic and resistance exercises. Weight reduction of about $2.7 \mathrm{~kg}$ was observed, favorable to combined intervention, and up to $4 \mathrm{~kg}$, when it was higher in intensity and length [35].

The regular practice of exercise results in a change in body composition and several physiological and metabolic benefits. In a study conducted in São Paulo, a oneyear intervention with physical activity and diet in obese adolescents, visceral fat loss was observed over time both in boys and in girls [36]. In Curitiba, a study group assessed the influence of dietary counseling and physical activity (three times a week), over a 24-week period on 64 obese adolescents. The study demonstrated a reduction in BMI and in waist circumference in both girls and boys, but with greater responses in boys. In obese adolescents with metabolic syndrome, there was also an improvement in cardiovascular risk factors such as a decrease in blood pressure, triglyceride levels, glucose levels and in insulin resistance (determined by HOMA$\mathrm{R})$, as well as an increase in HDL-cholesterol levels [37]. It was also noted in this study that, the reduction in insulin resistance was associated to weight loss. However, even in adolescents who did not lose weight, there was an improvement in insulin sensitivity through physical activity, probably resulting from metabolic conditioning. Physical activity is able to improve insulin sensitivity in a single exercise session, due to the increase in glucose uptake by the muscle, but it returns 
to the initial levels 48 hours after finishing the exercise. In order to obtain proper metabolic conditioning, exercise must be practiced regularly [38].

In addition to reducing risk factors, exercise promotes changes in other factors. It improves endothelial function; decreases proinflammatory cytokine levels; reduces stress levels in adults, children and adolescents; preserves lean muscle mass in weight loss programs and improves appetite control in previously sedentary individuals[39,40].

There is ongoing debate about the best exercise for children or adolescents to lose weight. In this age range, specific recommendations for physical activity - type, intensity, length and frequency - vary widely. The prescribed exercise type and "dosage" for a certain individual will depend on the goal to be reached, i.e., losing weight, controlling comorbidities, physical conditioning, preventing obesity and weight recovery [41].

It has been suggested that in order to obtain beneficial health effects, mainly in order to reduce cardiovascular risk factors, school-age children should participate in daily moderate to intense physical activities, for $60 \mathrm{~min}$ utes or more, as well as reducing sedentary behavior to less than two hours a day $[42,43]$. However, several studies have shown that both obese children and adolescents respond well to 30-40 minutes of physical activity, 3 times a week, improving cardiovascular conditioning and the metabolic syndrome components such as hypertriglyceridemia, hyperinsulinemia and arterial hypertension, even if weight loss is minimal, as long as the intervention is continuous and combined with good dietary counseling [44,45]. The most indicated exercise for weight loss and to reduce metabolic changes is aerobic exercise (jogging, swimming, cycling and other leisure activities [42].

Physicians must pay attention, as adolescents change their mind all the time, and they must practice the type of physical activity they decide to, and switch it whenever they want. Very often, patients do not want or do not like doing exercise. It is necessary to identify the restraints which keep adolescents from participating in activities [46-48]. It is important to emphasize to patients and their family that exercise does not have to be competitive, and that the main goal is to improve physical conditioning, to reduce weight and comorbidities. The compliance to physical exercise, at this age range is the same as in adults, i.e., 20 to $80 \%$. Frequently, obese children or adolescents have low physical conditioning. Their perception of effort is higher than the perception of thin individuals, and skeletal muscle pains are common, as a result of excess weight [49]. Therefore, it is important to establish progressive goals (mainly regarding intensity and volume of activities) until each patient meets the goals assigned to them.
Encouraging them to keep a diary recording the number of hours spent watching TV, at the computer or playing games and the frequency of physical activity also helps the follow-up process. Obesity is a chronic disease which affects individuals of all age ranges and is difficult to handle. Lifestyle changes are essential for the treatment to succeed. Among such changes, reducing sedentary life and practicing regular physical activity stand out, mainly during childhood and adolescence, when therapeutic pharmacological options are difficult.

The prescription of physical activity to children and adolescents requires extensive integrated work among multidisciplinary teams, patients and their families, in order to reach therapeutic success.

\section{Pharmacological Treatment of Obesity in Children and Adolescents}

The pharmacological treatment of obesity in children and adolescents has as its main difficulty in the fact that studies showing evidence about most drugs available in the market are lacking for such age group. At present, the drugs available for the treatment of obesity are: sibutramine, orlistat and catecholaminergic agents (diethylpropione, fenproporex and mazindol) [50] The choice criterion for which drugs to treat obesity with at such an age range follows the same standards suggested for the treatment of adults. In the case of food compulsion or lack of satiety, sibutramine is the most indicated drug [51]. Orlistat is more frequently indicated when there is excessive food intake, including high-fat diets. In order to use this drug, the absence of severe gastrointestinal disease must be confirmed [52]. Regarding catecholaminergic agents, there is no global experience, not even in adults, with relevant scientific studies. It can be indicated for attention-deficit disorder [50], which is not uncommon in obese children, because diethylpropione and fenproporex have structural similarities to methylphenidate, the drug of choice for this disorder. Thus, when it comes to obese children with attention-deficit disorder, rather good results may be obtained with diethylpropione, fenproporex and even mazindol, although it is a drug with no phenylethylamine nucleus. Topiramate is a drug which has already been tested for obesity [53], with good results, but due to side effects has not been released in the market for such a purpose. However, it has been increasingly used, mainly on individuals with mood disorders and food compulsion and it is important to emphasize that it is contraindicated for patients with a history of kidney stones. Bupropion is one of the drugs of choice for tackling tobacco addiction, but it may also work as an anti-obesity drug [54], although contraindicated for epileptics. Fluoxetine is a serotonin reuptake inhibitor which may help treat obesity [3], particularly when associated with arterial 
hypertension or sleep apnea. Relative contraindications are bipolar disorders and epilepsy. It can be inferred that the drug choice will depend on the patient's personality, behavior, dietary habits and associated diseases [55].

There are a few studies with metformin (a drug which increases hepatic insulin sensitivity) in obese non-diabetic and insulin-resistant adolescents, demonstrating that it may be a useful drug to fight obesity in children [56-58]. The longest was a year-long study which demonstrated reduced BMI and insulin resistance measured by HOMA-R in 28 obese adolescents with a dose of $2 \mathrm{~g}$ of metformin per day [58].

In an orlistat placebo-controlled study which included 539 obese adolescents, followed for 12 weeks, it was observed that associated risk factors improved and there was variable weight loss, up to $15 \mathrm{~kg}$ in some cases, with reduced insulin levels [7]. A 12-week study [59] also showed important results in all associated comorbidities; on the other hand, the concern with gastrointestinal effects in children seems unjustified, as according to such studies and to our experience, they do not seem to be more severe than in adults. The weight-independent effects of orlistat are described as improvements in cholesterol and hepatic enzyme levels, lower increments of postprandial triglyceride levels and increased insulin sensitivity [9].

Two important sibutramine studies have been conducted with obese adolescents and published in literature. One of them was conducted in Brazil [60] for 12 weeks and demonstrated important results in weight reduction when compared to placebo. The other study included 498 obese adolescents, followed for 12 months, and showed equally important weight-related results and co-morbidity improvements with sibutramine [61]. Its side effects in adolescents were the same and at a similar proportion to events reported by adults [51].

Taking into account the studies so far including children and adolescents, the use of metformin, orlistat and sibutramine is indicated starting from 10 years of age (for type 2 diabetes treatment), 12 years of age and 16 years of age (for obesity treatment), respectively.

However, this does not mean that pharmacological treatment must not be used in lower age groups. In severe cases of obesity, when health risks are extremely evident, the aim is to prevent early co-morbidity and mortality.

\section{Dyslipidemia}

Dyslipidemia in children and adolescents has become a frequent clinical condition, especially due to the increase in overweight and obesity prevalence in this age range [62]. Treatment depends on the type of dyslipidemia, i.e., if the cause is familial, with clinical signals such as xanthomas or if dyslipidemia is inserted in the global picture of metabolic syndrome. The lipid profile is completely diverse: while in familial dyslipidemia there is significant hypercholesterolemia with LDL-c levels possibly over $400 \mathrm{mg} / \mathrm{dl}$ [63] in dyslipidemia associated with metabolic syndrome, there is a higher trend of hypertriglyceridemia, low HDL-c levels, and LDL-c levels without quantitative but rather qualitative changes, such as small dense particles which are more atherogenic [64]. Dyslipidemia at this age range may have a genetic component with or without the environmental component, such as improper diet, familial hypercholesterolemia, familial combined hyperlipidemia and hypertriglyceridemia, and there may be types of dyslipidemia which are predominantly environment-related, but which may also have a genetic component, and in such cases excess weight or weight gain is extremely important [64].

\section{Prognosis}

The prognosis depends on the type of dyslipidemia, and it is well established that hypercholesterolemia, in its homozygotic form, is extremely severe [65] with a prevalence of $1 / 1$ million. Male children usually of 15 years of age may already present a coronary event or death. The heterozygotic form has a prevalence of $1 / 500$ [63]. Women have a better evolution with longer life expectancy than men, most of whom have already been diagnosed with coronary disease by the age of 50 years old [63].

For dyslipidemia associated with metabolic syndrome, recent data [63] have shown that the presence of metabolic syndrome during childhood is associated with the development of coronary disease 25 years later, i.e., in adulthood [66].

\section{Lipid Profile Assessment}

When should the lipid profile of children and adolescents be assessed? The $20051^{\text {st }}$ Guideline for Atherosclerosis Prevention in Children and Adolescents [67] recommends that every child over 10 years old assesses their cholesterol levels (Table 2). It is still being discussed if the most indicated assessment would be by capillary blood (simple trial) or by total venous blood

Table 2 Recommended lipid levels in adolescents up to 19 years old

\begin{tabular}{llll}
\hline Lipides & $\begin{array}{l}\text { Desired } \\
(\mathbf{m g} / \mathbf{d l})\end{array}$ & $\begin{array}{l}\text { Coterminous } \\
(\mathbf{m g} / \mathbf{d l})\end{array}$ & $\begin{array}{l}\text { Increased } \\
\mathbf{( m g / d l})\end{array}$ \\
\hline $\mathrm{TC}(\mathrm{mg} / \mathrm{dl})$ & $<150$ & $150-169$ & $\geq 170$ \\
$\mathrm{LDL}-\mathrm{C}(\mathrm{mg} / \mathrm{dl})$ & $<100$ & $100-129$ & $\geq 130$ \\
$\mathrm{HDL}-\mathrm{C}(\mathrm{mg} / \mathrm{dl})$ & $\geq 45$ & & \\
$\mathrm{TG}(\mathrm{mg} / \mathrm{dl})$ & $<100$ & $100-129$ & $\geq 130$ \\
\hline
\end{tabular}

TC: total cholesterol; LDL-c: LDL-cholesterol; HDL-c: HDL-cholesterol; TG: triglycerides. 
(to determine the full lipid profile). Such recommendations are more important when children present any of the risk factors listed below:

1. Family history of early atherosclerosis in parents, siblings or grandparents (before 55 years old in men and before 65 years old in women);

2. If parents have cholesterol levels $>240 \mathrm{mg} / \mathrm{dl}$;

3. If children have other associated risk factors, such as hypertension, obesity and saturated fat or trans fatty acid rich diet;

4. Children who have other diseases which may be associated with dyslipidemia, such as AIDS and hypothyroidism;

5. Children who use drugs which may predispose them to dyslipidemia, e.g., isotretinoin for acne;

6. Children who present clinical manifestations of dyslipidemia, even if they are not pathognomonic, such as xanthoma and/or xanthelasma - they are strong indicators - and occasionally the presence of repeated pancreatitis in children who have hypertriglyceridemia.

The new recently published American Guideline in Pediatrics [68] brings some important differences regarding treatment:

1. Always initiate the treatment with non-pharmacological measures;

2. Age of starting pharmacological treatment reduced from 10 to 8 years old;

3. If the child is healthy and does not present other problems, the LDL-c level limit for pharmacological treatment is $190 \mathrm{mg} / \mathrm{dl}$;

4. If the child has important family history or two risk factors, the LDL-c level limit decreases to $160 \mathrm{mg} / \mathrm{dl}$;

5. If the child is diabetic, the limit LDL-c level is $130 \mathrm{mg} / \mathrm{dl}$

However, the early pharmacological treatment motivated an editorial published in New England [69]. The author demonstrates concern with the use of drugs in situations that could be reverted by intensifying lifestyle changes.

\section{Classification of Familial Hypercholesterolemia}

Although most of this review focuses on metabolic syndrome, we also need address hypercholesterolemia in children.

Several mutations in several locations could result in familial hypercholesterolemia, such as: mutation in the LDL receptor [10], mutation in Apo B-100 [70] and mutation in protease PCSK-9, which destroys LDL receptors decreasing their half-life [70]. A certain mutation of such protease would result in longer receptor half-life with lower prevalence of coronary disease [71]. Recently, such a mutation was identified in black and Caucasian populations, but the effect observed in the black population was more intense. They have LDL-c levels approximately $30 \%$ lower than those observed in the average New York population; at the same time, they presented $88 \%$ lower cardiovascular mortality rates. Considering the pharmacological intervention studies, for each $\mathrm{mg} / \mathrm{dl}$ of LDL-c level reduction observed with the treatment, it is possible to decrease the prevalence of coronary disease by about $1 \%$. Thus, we may infer that in this NY population, the lowest mortality rate was superior to the expectations of the lowest LDL-c levels [71]. It is believed [72] that such a difference is due to the fact that the low LDL-c levels observed in this population have been the same in these individuals since birth, different from the treatment with statins which was usually initiated in clinical studies, in adulthood.

\section{Diagnosis of Familial Hypercholesterolemia}

For the diagnosis of familial hypercholesterolemia, two non-exclusive but complementary strategies may be used: 1) Cascade trial - which in selected cases are researched due to personal and/or family history. In a case of hypercholesterolemia or early coronary disease (men under 55 years old and women under 65 years old), descendants and family members are called for a lipid profile assessment. In such cases, the new American Guideline already recommends the trial in one-yearolds [68]. 2) Generalized trial - all children are assessed. Considering the difficulties in obtaining the genetic diagnosis, if children present LDL-c levels over 95 percent for their age range and gender and if there is family history of early coronary disease, the diagnosis is probably familial hypercholesterolemia[68], and the treatment is often initiated immediately, especially in cases of tendinous xanthoma.

\section{Treatment}

1. Non-pharmacological, including diet, physical activity and phytosterols.

\section{Pharmacological}

Cholestyramine has always been accepted as the first-line therapy drug for children due to it being a resin which is not absorbed in the intestines; its effect is intestinal, not systemic. It may affect the absorption of liposoluble vitamins, which may result in important side effects in children. The main side effect presented is intestinal obstipation, therefore it is better tolerated by children than by the elderly [73]. Cholestyramine has a reduced effect in decreasing LDL-c levels (< $19 \%)$, as every intestinal-acting drug tends to have a diminished effect due to intestinal adjusting (when cholesterol absorption decreases in the intestine, a chylomicron particle with lower cholesterol levels is generated and as it reaches the liver, it stimulates a higher expression of the LDL receptor in order to increase cholesterol reception) [73]. 
The 2008 Pediatrics Guideline already determines statin as the first-line drug for treating hypercholesterolemic children other than cholestyiramine [68]. The drug ezetimibe acts specifically in cholesterol absorption, decreasing LDL-c levels by $20 \%$, further decreasing it when associated with statin[74]; it may also be used alone or in association.

Statins have been used in adults since 1987, but longterm studies still need to be conducted regarding its prescription to children and adolescents in order to determine the safety of using it over 20 or 30 years and if its continued use is associated with the improvement of clinical endpoints [13]. Side effects are similar to those observed in adults, and there has been no evidence of change in the growth, sexual and cognitive development curves [75-77], as the decrease in cholesterol synthesis does not compromise hormonal synthesis or brain development [78].

Using fibrate and nicotinic acid in children and adolescents is recommended only in exceptional situations, as with fenofibrate, which is used when non-pharmacological measures are ineffective at treating hypertriglyceridemia [73]. However, further studies must still be conducted regarding the use of these drugs for such an age range [68].

Using statin presents other benefits, such as the improvement in flow-dependant endothelial function [79] and the improvement in the progression of the carotid intima-media thickness in individuals with familial hypercholesterolemia. A study conducted in the Netherlands demonstrated that the treatment of familial hypercholesterolemia, when initiated at 10 years old, changes the perspective of individuals [78].

It is concluded that, for dyslipidemia in children and adolescents, family history and all the risk factors must be assessed in order to determine the best therapeutic strategy which allow the goals established for their age range to be reached, thus preventing clinical cardiovascular endpoints.

\section{Hypertension in Children and Adolescents}

The global increase in the prevalence of obesity, which has also affected children and adolescents, is favoring an increase in blood pressure and therefore, the prevalence of arterial hypertension [80]. The impact of weight gain on blood pressure is not the same in all age ranges nor is it between men and women. In the young male population, divided into quartiles according to body mass index (BMI), an increase in the prevalence of arterial hypertension can already be seen in the second quartile. The association of BMI and hypertension is greater among men below 45 years of age and in this subpopulation, $60 \%$ of the hypertension cases can be attributed to excess weight.
In women under 45 years old, the impact of weight gain on the prevalence of arterial hypertension is lower, compared to men. Above this age however, an evident association between BMI and hypertension prevalence has been observed. It is likely that in women above 45 years old or in menopause, weight gain associated with the accumulation of abdominal fat favors the increased prevalence of hypertension.

\section{Physiopathological Mechanisms Associated to Arterial Hypertension in Metabolic Syndrome}

The possible mechanisms that trigger arterial hypertension associated with metabolic syndrome are mainly related to the presence of visceral fat, which results in insulin resistance. The subsequent hyperinsulinemia promotes the increase in sodium absorption by the kidneys, which favors arterial hypertension [81]. In addition, hyperinsulinemia also increases the sympathetic activity, which contributes to the development of arterial hypertension [81].The accumulation of visceral fat elevates the activity in the renin-angiotensin system, due to an increased production of angiotensinogen, which consequently favors arterial hypertension [82,83]. Experimental studies have yet indicated that leptin could be another factor within the physiopathology of arterial hypertension as it causes the sympathetic activity to increase [84].

\section{Arterial Hypertension Diagnosis in Children and Adolescents}

Arterial hypertension should be measured in every child as of three years old, mainly when there are family risk factors. The method of choice is auscultation. The child should be in a sitting position and at ease, preferably leaning against the backrest and with their feet supported; the right arm should be at the same level as the heart and blood pressure should be taken on at least three different occasions. The diagnosis of hypertension if blood pressure is altered in these three occasions was established. Systolic pressure is determined by the first Korotkoff sound and the diastolic by the fifth sound. It is important to notice the size and the location of the cuff, which should cover $40 \%$ of the circumference of the arm, mid length between the acromion and the olecranon, and the stethoscope should be placed in the cubital fossa. These recommendations are important for measuring blood pressure adequately. The normal levels of blood pressure are based on gender, age and percentile of height and are presented in tables which can be used to determine whether the individual is hypertensive or normotensive [85]. Some programs are already available on the Internet. By inserting the child's age and height, as well as systolic and diastolic blood pressure, the information on the percentile the child is in 
regarding arterial blood pressure is obtained, which enables the determination of whether the child is hypertensive or not.

Arterial Blood Pressure Monitoring in children and adolescents shows an increase in systolic blood pressure with age. Daytime blood pressure is more elevated than nighttime blood pressure. Other similar studies have shown that systolic blood pressure varies much more than diastolic blood pressure with reference to age.

Considering that blood pressure changes constantly throughout childhood and that there are modifications of normal values depending on gender, age and height, normal blood pressure in children is defined as systolic or diastolic blood pressure below the $90^{\text {th }}$ percentile [85].

Pre-hypertension is defined when the child presents blood pressure between the $90^{\text {th }}$ and $95^{\text {th }}$ percentiles, or in adolescents when blood pressure is greater than 120/ $80 \mathrm{mmHg}$. Stage 1 of arterial hypertension is defined when the child presents blood pressure between the $95^{\text {th }}$ and $99^{\text {th }}$ percentile with the addition of $5 \mathrm{mmHg}$, and stage 2 when the pressure levels are above the $99^{\text {th }}$ percentile with the addition of $5 \mathrm{mmHg}$ [85].

An increase in blood pressure is associated with lesions of target organs, which has been shown in the Rio de Janeiro Study. This study demonstrated an association of BMI, increase in blood pressure and hypertrophy in the left ventricle, measured either in grams or by the left ventricular mass index [86]. The comparison between the hypertensive group (blood pressure scores above the $95^{\text {th }}$ percentile) and normotensive group (blood pressure values below the $50^{\text {th }}$ percentile) showed a significant difference in the left ventricle mass in these adolescents. A third group which presented variable blood pressure, sometimes above the $95^{\text {th }}$ percentile and sometimes below these values, presented intermediary left ventricle mass which indicates that alterations in target organs, from very early stages of blood pressure level elevation, can already be observed.

\section{Treatment}

It is important to remember that arterial hypertension in children and adolescents, even when associated with obesity, demands investigation for the diagnosis of secondary hypertension because the younger the child and the more elevated the levels of blood pressure, the greater the chance of developing secondary hypertension.

In the pre-hypertension phase (between the $90^{\text {th }}$ and $95^{\text {th }}$ percentiles, or blood pressure above $120 / 80$ $\mathrm{mmHg}$, but lower than the $95^{\text {th }}$ percentile in adolescents), the recommendation is lifestyle [87] changes which promote weight loss and the improvement of insulin sensitivity.
Drug treatment is indicated for stage 1 hypertension, or upon the presence of symptoms (headaches or lightheadedness) or when there is no response to the immediate lifestyle changes for a period of at least six months, especially when there is a family history of hypertension or premature cardiovascular disease [85]. The goal of the therapy is to obtain blood pressure levels below the $95^{\text {th }}$ percentile. However, in the presence of target organ lesions or other cardiovascular risk factors - like type 1 diabetes (T1D) with nephropathy or even T2D - the goal is to obtain levels below the $90^{\text {th }}$ percentile.

In stage 2 hypertension, the goals are similar to those described for stage 1 . The treatment should also aim at reducing cardiovascular morbi-mortality in the long run, although no studies conducted with children show that arterial hypertension treatment will result in morbi-mortality reduction.

There is no consensus regarding the best pharmacological agent to be used when initiating essential hypertension therapy in children. It is suggested that the smaller dose be used, enough to be effective and that it does not cause side effects. In choosing anti-hypertensive drugs however, we should preferably choose those which will not enhance insulin resistance, promote weight gain (beta-blockers), or worsen glucose intolerance (thiazide diuretics) or the lipid profile, and that are able to control blood pressure for 24 hours. The presence of other cardiovascular risk factors should also be considered such as microalbuminuria, which reflects a systemic endothelial lesion not restricted to the glomerulus, as well as a hypertrophy of the left ventricle.

Lifestyle change measures should always be implemented as early as possible, as it is easier for children to change life habits. A controlled consumption of salt from the early months of life is recommended, fighting excess weight from the first year of life and always encouraging the premature practice of physical activity, along with healthy eating habits.

In drug treatments of hypertension associated with metabolic syndrome, the mechanisms which generate hypertension such as the increase in activity of the renin-angiotensin system and sympathetic system as well as the increase of sodium absorption, should be interfered with if possible always with the aim of decreasing cardiovascular morbi-mortality. The drugs more widely used and their mechanisms of action are listed below:

1. Angiotensin receptor blockers and converting enzyme inhibitors (ACEIs) inhibit the renin-angiotensin system and reduce cardiovascular mortality in adults. In the ACEI class, the drugs suited for pediatric use are benazepril, captopril, enalapril [88], fosinopril[89], lisinopril [90] and quinapril. These drugs are totally 
contraindicated during pregnancy and, thus, when used by women or teenage girls of fertile age, they must be accompanied by the use of safe contraceptive methods. It is always necessary to evaluate the levels of potassium and creatinine during therapy and coughing is a frequent side effect. The FDA in the United States has approved the use of ACEIs in children over six years old and for individuals with creatinine depuration above $30 \mathrm{ml} / \mathrm{min}$, as this condition offers a lesser risk of hyperkalemia. These drugs present advantages, when used on adults, for individuals with insulin resistance, as they are associated to a lower risk of diabetes onset [91]. The angiotensin II receptor blockers (ARBs) approved for use by children are losartan and ibesartan. These are also contraindicated during pregnancy and recommendations are similar to doses described for ACEIs. Losar$\tan$ has the advantage of being available in suspension formulation, although not in Brazil. The use of ARBs can also be associated with a lower incidence of diabetes, and these agents can be used for long periods, as they are very well tolerated, due to their effects being similar to placebo.

2. Calcium channel blockers (CCBs) promote natriuresis and have a vasodilating action; amlodipine, felodipine, isradipine and slow-release nifedipine are approved for pediatric use. Amlodipine and isradipine are available, in the United States, in suspension formulation, which favors its use by children.

3. Beta-blockers have been recommended for young patients for a long time and the agents bisoprolol, metropolol, propanolol, labetalol (alfa and beta) are approved for use by children and adolescents. The efficacy of metropolol was demonstrated in a clinical trial involving 140 children, showing to be effective in the $2 \mathrm{mg} / \mathrm{kg}$ dose [92]. Non-cardioselective agents should not be used in patients with asthma or heart failure, and their heart rate defines the dose to be used. These drugs can reduce the individual's performance during physical activity. These are not the most indicated drugs for diabetic patients using insulin as they favor hypoglycemia, unless under specific indications. Also, in individuals with insulin resistance, it has been shown that these agents increase the incidence of diabetes [93].

4. Diuretics such as hydrochlorothiazide, clortalidone, furosemide, espironolactone, trianterene and amiloride can be used. Thiazides and sub-products, as well as furosemide are more effective as anti-hypertensives than espironolactone and trianterene. Experience with adults has shown that the use of low doses of thiazides is effective as an antihypertensive. In association, diuretics have the ability to increase the efficiency of other antihypertensive agents which act by other mechanisms. Thiazides promote hypokalemia, an undesireable side effect, as it worsens glucose intolerance. This effect is dose- dependent and can be minimized if associated with a renin-angiotensin system blocker, an ARB or an ACEI, which favor potassium retention. Potassium-sparing diuretics are less effective and caution is necessary because when associated with ACEIs or ARBs, there is an increased chance of hyperkalemia. Furosemide can be indicated when edema is present, but can be useful in young patients with resistant hypertension, associated with other drugs, as well as in children with kidney failure.

5. Blockers of the sympathetic nervous system, peripheral alpha and beta-blockers and centrally acting alpha agonists such as clonidine, are considered in the treatment of resistant hypertension or when complications present, such as kidney failure. Clonidine causes side effects such as xerostomia, sedation and nasal obstruction. They are available in the American market in transdermic preparation, and their abrupt interruption could cause a hypertensive crisis due to an adrenergic discharge. Peripheral blockers like prazosin and doxasosin, are more widely used these days in association, and their advantage is the non alteration of the metabolic profile, as they even improve insulin sensitivity. The side effects are syncope, especially after the first dose and water retention. In the ALLHAT study, the use of prazozin was associated with negative endpoints and showed an increased incidence of heart failure.

6. Vasodilators like hydralazine and minoxidil are indicated when the blood pressure cannot be controlled, especially in children with kidney failure. These agents can cause tachycardia and water retention, and the concomitant use of diuretics may become necessary, especially in kidney failure, as well as the use of betablockers, for the reduction of heart rate. Hydralazine can cause lupus-like syndrome and the prolonged use of minoxidil can trigger hypertrichosis.

It can be concluded that anti-hypertensive treatment in children and adolescents should follow a customized plan according to the clinical condition and metabolic profile of the patient, having the reduction of cardiovascular morbimortality as the primary goal.

\section{Type 2 Diabetes in Children and Adolescents}

The prevalence of type 2 diabetes mellitus (T2D) in children and adolescents has increased over the last 20 years in many countries and several ethnic groups [94]. In the USA, it has been indicated as an epidemic: $80 \%$ of Caucasian diabetic children over 10 years old had type 1 diabetes mellitus (T1D). On the other hand, 46\%$86 \%$ of Afro-American, Hispanic, Asian-descendant or Amerindian-descendant children have been diagnosed with T2D [95]. In Europe and South America, the prevalence of T2D in children and adolescents is lower [96-99], but a German study showed that $2.5 \%$ of 
700 obese school-age children presented impaired glucose tolerance (IGT) or diabetes [100], while an Argentinean study observed $1.6 \%$ of T2D and $7 \%$ of IGT in obese children [101]. In Japan, from 1976 to 1997, a ten-fold increase was observed in the presence of glucose abnormalities at the pediatric age range, a process which has been reverted through the adoption of public policies aiming at improving dietary habits [102].

In Brazil, there are few data on T2D prevalence in the young population. A study conducted in Fortaleza assessed 720 school-age children and found that capillary glucose levels were higher than normal in $8.3 \%$ of young people from 14 to 19 years old, most of whom were female [103]. At the childhood obesity clinic of The Group of Obesity in Hospital das Clinicas (University of Sao Paulo), abnormal fasting glucose levels and/ or IGT were found, respectively, in $5 \%$ and $2.5 \%$ of the population studied (personal communication by Sandra M. F. Villares).

\section{Pathophysiology}

The etiology of T2D in children and adolescents is multifactorial, similar to the one affecting adults, involving genetic and environmental factors; it results from the combination of insulin action resistance and $\beta$ cell function failure. Insulin resistance is strongly associated with obesity, particularly central adiposity. This is believed to be the first abnormality in diabetes, preceding insulin secretion failure [104]. There is a $50 \%$ reduction in sensitivity and approximately $75 \%$ lower first phase insulin secretion in type 2 diabetic adolescents as compared to controls of non-diabetic obese individuals [105]. Insulin secretion failure seems to be more severe than the one observed in adults.

In adolescents at high risk of diabetes, the transition from normal tolerance to impaired glucose tolerance or pre-diabetes is associated with quick weight gain and a decrease in insulinogenic index, while the progression to T2D correlates to greater weight gain, reduced insulin sensitivity and a dramatic decrease in insulin secretion [106]. In type 2 diabetic adolescents, the decrease in $\beta$ cell function, observed over 6 years of follow-up, was approximately $15 \%$ per year with no significant changes in insulin sensitivity [107]. Such loss of function is more than double and faster than the one observed in adults in the UKPDS study, which was 7\% per year [108].

Additionally, T2D is commonly associated with other factors related to insulin resistance, such as hyperlipidemia, hypertension and non-alcoholic hepatic steato$\operatorname{sis}[109]$.

\section{Risk Factors for Type 2 Diabetes}

The risk factors for T2D in young people include: family history, race and ethnicity, obesity and a sedentary lifestyle. The risk of developing T2D is 5 times higher for individuals with first-degree relatives with T2D as compared to controls of the same gender, age and weight with no family history of diabetes [110]. Determining factors for such risk are already present in fetal life.

The risk of metabolic syndrome during childhood was higher when neonates were on the weight curve extremities, i.e., large for gestational age (LGA) or small for gestational age (SGA). Similarly, children born from mothers with gestational diabetes mellitus have higher risk of developing T2D in adulthood [111,112].

In the USA, as previously described, T2D is two to six times more prevalent in African-American, Hispanic, Asian-descendant and Amerindian-descendant populations than in non-Hispanic Caucasians [113].

Several studies show that obesity associated with insulin resistance and T2D mellitus has largely increased in populations which have westernized their lifestyle, i.e., which have started consuming high-calorie diets and reduced physical activity [114].

Polycystic ovary syndrome (PCOS) and acanthosis nigricans are conditions associated with insulin resistance. A clinical study has shown that 30 to $32 \%$ of young women between 14 and 19 years old with PCOS had impaired glucose tolerance $[115,116]$. Acanthosis nigricans, a disorder related with the activation of insulin receptors in the skin by insulin excess, is present in 90\% of T2D children [115,117-119].

During puberty, there is a physiological peak of insulin resistance around Tanner stages 2 and 4, which returns to normality in early adulthood. Its peak occurred at Tanner 3 in both sexes, and girls were more insulin resistant than boys at all Tanner stages The diagnosis of T2D in young people occurs more frequently during the second decade of life, and the average age of diagnosis is 13.5 , coinciding with the physiological peak of insulin resistance $[29,31,120,121]$.

\section{Classification and Diagnosis of Diabetes in Childhood}

The criteria for diagnosing diabetes in childhood are based on glucose levels and the presence of symptoms [122]. There are three possibilities for diagnosing diabetes, which, in the absence of unequivocal hyperglycemia symptoms, must be confirmed by dosages in subsequent days, as follows:

1. Fasting glycemia $>126 \mathrm{mg} / \mathrm{dl}$,

2. Post-overload glucose levels with $1.75 \mathrm{~g} / \mathrm{kg}$ of anhydrous glucose up to $75 \mathrm{~g}$ dissolved in water, $\geq 200 \mathrm{mg} / \mathrm{dl}$

3. Classic symptoms of diabetes and casual glycemia $\geq 200 \mathrm{mg} / \mathrm{dl}$, where 'casual' is defined as any time of day, not related to the last meal, and 'classic symptoms' include polyuria, polydipsia and unexplainable weight loss. 
However, similarly as in adults, glycemic values often do not reach those established for diagnosing diabetes, but they are too elevated to be considered normal and must be classified as impaired fasting glucose levels ( $\geq$ $100 \mathrm{mg} / \mathrm{dl}$, but $<126 \mathrm{mg} / \mathrm{dl}$ ) or impaired glucose tolerance, 2 hours after glucose overload, glycemic levels above $140 \mathrm{mg} / \mathrm{dl}$, but lower than $200 \mathrm{mg} / \mathrm{dl}$.

On the other hand, images shown as type 1 diabetes (T1D) stereotypes - skinny children, with abrupt clinical condition - are characteristics that are no longer typical of the condition. Approximately one quarter of T1D patients may be obese at the moment of diagnosis. T1D may be confirmed by the $90 \%$ presence of anti-pancreatic antibodies at the moment of diagnosis, while the other $10 \%$ may have T2D, MODY or other types of diabetes (Tables 3 and 4).

Research is recommended through antibodies dosage in overweight or obese children over 13 years old with clinical features of T1D mellitus, i.e., weight loss and ketosis or ketoacidosis (Figure 1).

Moreover, investigating the $\mathrm{C}$-peptide levels is indicated for obese or overweight children over 13 years old, who have evolved with significant worsening of glycemic control during oral drug treatment. Plasma Cpeptide levels over $1 \mathrm{ng} / \mathrm{mL}$ one year after diagnosis are highly suggestive of T2D [123,124].

It is recommended to assess all children and adolescents considered at risk of T2D (Table 5), from 10 years old or at early puberty stage, if first, and it must be repeated every two years. Fasting glycemia is the initial test recommended by the American Diabetes Association, due to its easy performance and convenience; even though data in literature show higher prevalence of impaired glucose tolerance and diabetes when glycemic curves are used for such assessments [123,125,126].

\section{Clinical Condition of Children with T2D}

Usually, typical T2D children or adolescents, similarly to adults, have few symptoms. There is also an intense family aggregation, as these children frequently have obese parents and first-degree relatives with T2D. Obesity may be predominantly visceral, with clinical features of metabolic syndrome and insulin resistance, such as: hypertension, hyperlipemia, sleep apnea, polycystic ovary syndrome and acanthosis nigricans. The initial condition of T2D in children or adolescents may be of hyperosmolar coma, currently known as the hyperglycemic dehydration syndrome [119]. This syndrome may affect up to $4 \%$ of the cases of T2D and presents mortality rates from $14 \%$ to $43 \%$ [127]. These children are as obese as adult type 2 diabetics, present change in level of consciousness (Glasgow scale on average from 9 to 15, but the impairment might be even more severe), average osmolarity of $400 \mathrm{mOsm}$ and glycemic levels around $600 \mathrm{mg} / \mathrm{dl}$. Usually, even after metabolic compensation, it may take from 1 to 7 days for the level of consciousness to return to normal [128-130]. In 5\% to $50 \%$ of the cases, T2D may manifest initially as diabetic ketoacidosis $[127,131]$.

\section{Treatment of Children with T2D}

T2D treatment goals in children and adolescents are: reducing weight gain; maintaining linear growth; increasing physical activity; normalizing glucose levels and controlling comorbidities, including hypertension, dyslipidemia and hepatic steatosis.

Table 3 Classification of Diabetes Mellitus in Children and Adolescents

\begin{tabular}{|c|c|c|c|c|}
\hline & T1D & T2D & ADM & MODY \\
\hline Age at onset & Childhood & Puberty & Puberty & Puberty \\
\hline Severity at onset & Acute/severe & $\begin{array}{l}\text { Moderate to severe, usually } \\
\text { insidious }\end{array}$ & Acute/severe & Mild/insidious \\
\hline Insulin secretion & Very low & Varying & Moderately low & Varying \\
\hline Insulin sensitivity* & Normal & Reduced & Normal & Normal \\
\hline Insulin dependency** & Permanent & No & Varying & No \\
\hline Genetic & Polygenic & Polygenic & $\begin{array}{l}\text { Autosomal } \\
\text { dominant }\end{array}$ & $\begin{array}{l}\text { Autosomal } \\
\text { dominant }\end{array}$ \\
\hline Ethnic and racial distribution & $\begin{array}{l}\text { All (less frequent in } \\
\text { Asians) }\end{array}$ & $\begin{array}{l}\text { Blacks, Hispanics, Asians and } \\
\text { Amerindians }\end{array}$ & Blacks & Caucasians \\
\hline $\begin{array}{l}\text { Frequency (of all DM types in children and } \\
\text { adolescents) }\end{array}$ & $\sim 80 \%$ & $10-20 \%$ & $5-10 \%$ & Rare \\
\hline $\begin{array}{l}\text { Association with } \\
\text { Obesity }\end{array}$ & No & Strong & Varying & No \\
\hline Acanthosis nigricans & No & Yes & No & No \\
\hline Autoimmunity & Yes & No & $\mathrm{No}$ & No \\
\hline
\end{tabular}

DM: diabetes mellitus; T1D: type 1 diabetes mellitus; T2D: type 2 diabetes mellitus; ADM: atypical diabetes mellitus; MODY: maturity-onset diabetes of the young or monogenic diabetes.

* insulin sensitivity: considered a pathogenic factor. **insulin dependency is diagnosed in the absence of acute disease or other stress factors [119]. 
Table 4 Distinguishing features of type 1 and type 2 diabetes mellitus

\begin{tabular}{lll}
\hline & T1D & T2D \\
\hline Start & Abrupt and symptomatic & Slow consolidation, with few symptoms \\
Family history & 5\% T1D & 75-100\% T2D \\
Insulin resistance & uncommon & common \\
Obesity & Obese, normal or thin & Typically present \\
Polidypsia, poliuria & symptomatic & Usually absent or mild \\
Ketoacidosis & $30-40 \%$ at diagnosis & $5-25 \%$ at diagnosis \\
Hypertension and hyperlipemia & - & + \\
Sleep apnea & - & + \\
Acanthosis nigricans & - & + \\
Polycystic ovary & - & + \\
C-peptide levels & Low & Normal or elevated \\
Anti-pancreatic antibodies & $+(70-90 \%)$ & Absent \\
Acanthosis nigricans & - & +
\end{tabular}

T1D: type 1 diabetes; T2D: type 2 diabetes.

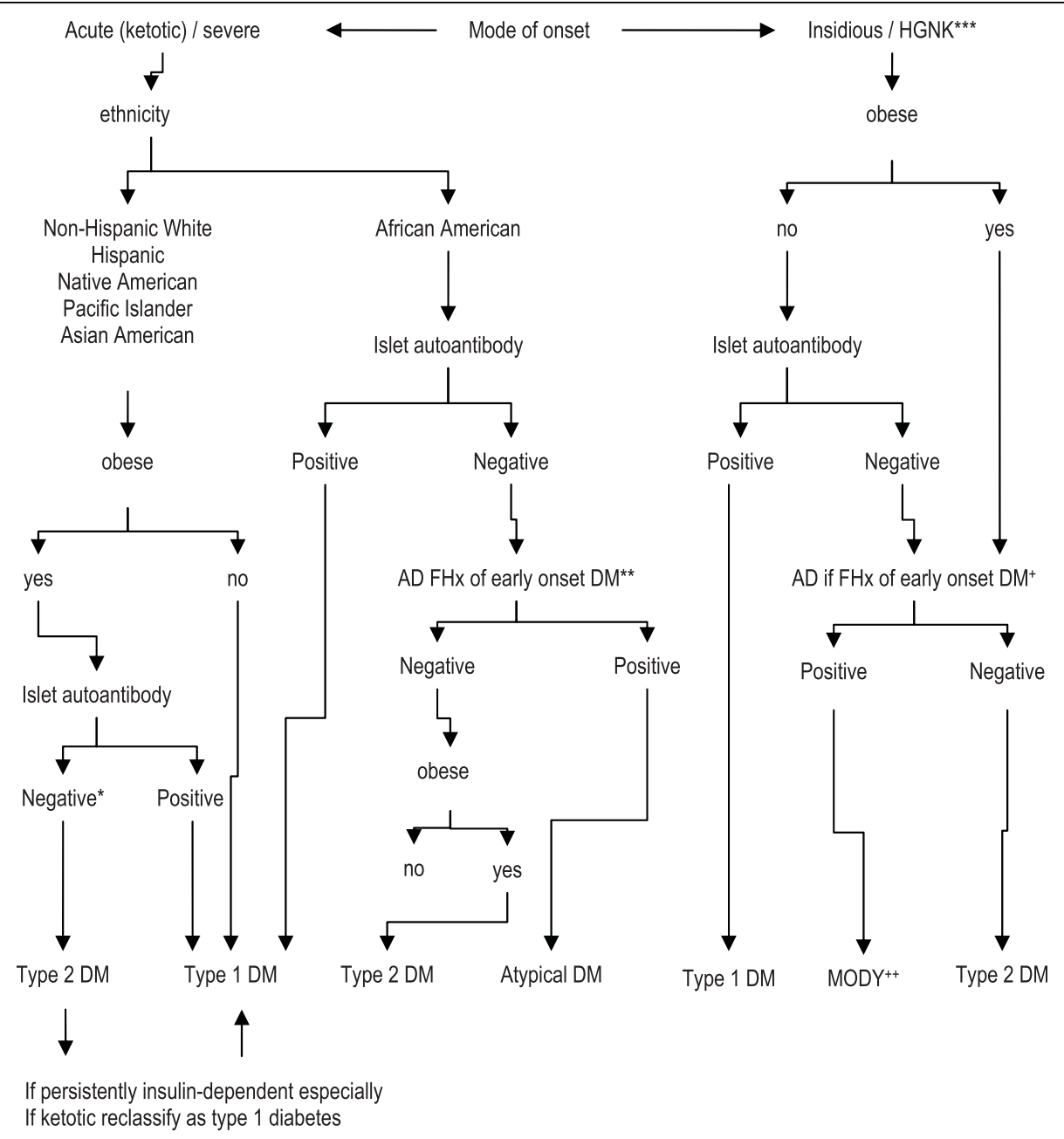

Figure 1 Clinical classification of diabetes mellitus in children. ${ }^{*}$ No-specific autoimmunity; ${ }^{* *}$ Autosomal dominant (AD) family history (FHx) of diabetes (DM) with an onset before 40 years of age; ${ }^{* * *}$ HGNK: hyperglycemia-nonketotic ${ }^{+}$Autosomal dominant (AD) family history (FHx) of diabetes (DM) in more than three generations. ${ }^{++}$Maturity-onset of diabetes of the young. Adapted from Rosenbloom, AL(127). 
After instituting non-pharmacological measures (diet and physical exercise), if results are not within the guideline targets for the specific age range, the introduction of metformin is recommended at half the dose usually prescribed to adults, increasing progressively up to $2 / 3$ of the maximum dose recommended for the adult population $[132,133]$. Metformin decreases hepatic glucose production and increases glucose capture by peripheral tissues, as well as improving insulin resistance, body composition, insulinemia and, in type 2 diabetic adolescents with polycystic ovaries, improves SHBG and androgenic levels $[42,44]$. While prescribing it to adolescents with ovulation disorders, the need for contraception must be considered, as there is a possibility of inducing ovulation and unplanned pregnancy. Metformin reduces glycosylated hemoglobin by up to $1.2 \%$, and abdominal pain is the most common side effect, affecting $25 \%$ of children [134,135].

If glycemic control is not achieved by lifestyle changes and metformin in monotherapy, the next therapeutic option would be sulfonylurea. It is known that these drugs increase both basal insulinemia as insulin secretion stimulated by food ingestion, leading to weight gain and higher risk of hypoglycemia [47]. The maximum dose recommended for children and adolescents corresponds to $2 / 3$ of the maximum dose for adults and the reduction in glycosylated hemoglobin is approximately $0.8 \%$ [123]. Sulfonilureas (e.g., glibenclamida, glicazida, glimepiride) act by increasing both basal and meal-stimulated insulin secretion these obsviously carry the side effects of increasing weight gain and risk of hypoglycemia. There are no data regarding the appropriate management of type 2 diabetes in childhood.

Introducing insulin is indicated when the glucose level targets have not been reached through dietary changes, physical activity and oral agents in monotherapy or in association. However, evidence shows that introducing insulin early in the adult population makes long-term glycemic control easier, which may perhaps revert damage caused by hyperglycemia to $\beta$ cells and insulin sensitivity [136-138]. Other medications employed in the T2D treatment of adults, such as glitazones, meglitinides, $\alpha$-glucosidase inhibitor, amylin (pramlintide), incretinomimetic (exenatide) and DPP-4 inhibitors (gliptins) are not approved for use in pediatric populations.

Insulin is the longest-standing and most effective treatment for diabetes, because it is able to reduce glycosylated hemoglobin (HbA1c) to normal levels. However, the use of insulin is associated with weight gain $(2-4 \mathrm{~kg})$, probably related to glycemic level correction and subsequent reduction in glycosuria, and increased risk of hypoglycemia, due to high glycemic control intensification, targeting $\mathrm{HbA} 1 \mathrm{c}$ levels lower than $7 \%$. As advised by the latest ADA/EASD consensus [139], basal insulin may be added to oral drugs (metformin or metformin and sulfonylurea). Treatment is generally initiated by administering a medium-acting insulin (NPH) or long-acting insulin analog (levemir or glargine) dose of 0.1-0.2 U/kg of weight before bedtime, and insulin dose adjustments must be made according to the fasting capillary glycemic levels, measured on a daily basis. The insulin dose must be increased by $2-4$ units every 3 days until reaching near-normal glycemic levels, with no unexplainable hypoglycemia.

After correcting fasting glycemia, glucose monitoring must be made at other times of the day, such as before dinner: if levels are proper, it is possible to infer that glycemic control goals have been reached. Another way of assessing the effectiveness of treatment is through the 8-point profile, i.e., measuring capillary glycemia before and after the 3 main meals, occasionally before bedtime and during the night, as well as fasting glycemia the following day, in order to identify moments when glycemic levels might be abnormal. It is suggested that measurements be made once a week or every 15 days, on different days of the week; however, this frequency may be individualized, depending on whether or not metabolic control is stable.

In the presence of hyperglycemia, when dieting errors and improper oral therapeutics are excluded, it is suggested to administer the second dose of NPH insulin before breakfast, which must be a 4-unit dose, and to maintain oral agents, progressively increasing the dose according to self-monitoring. However, a few patients may reach pre-prandial glucose targets and have hyperglycemia after meals, due to dieting errors or failure of 
oral agents indicated to control postprandial glucose levels. If dieting errors are corrected by keeping similar amounts of carbohydrates at each meal and postprandial hyperglycemia still occurs, it is suggested to introduce fast-acting or ultrafast-acting insulin before the "troublesome" meal, instead of an additional NPH insulin dose. In such case, fast-acting insulin before meals is recommended initially at a 4-unit dose, progressively increased based on postprandial glucose levels.

Diabetes mellitus is an evolutionary disease with progressive reduction in the number of $\beta$ cells able to produce insulin, leading to insufficient secretion of the hormone and subsequent hyperglycemia, even in the presence of oral drugs and insulin therapy $[140,141]$. In this situation (beta-cell failure), intensive insulin therapy is indicated, where basal insulin (multiple doses of NPH or of long-acting analogs) is associated with fast-acting or ultrafast-acting insulin before the main meals. The therapy prescribed shall be basal-bolus insulin therapy, similar to the one recommended for treating T1D patients.

\section{Complications}

In this age range, T2D evolves with more comorbidities than T1D [142,143]. Microvascular chronic complications, such as retinopathy, incipient nephropathy (microalbuminuria) and peripheral neuropathy, and macrovascular chronic complications are the most prevalent, and they decrease life expectancy and quality [143]. Table 6 shows the comparison made between young Australian populations under 18 years old with type 1 and T2D. In relation to the complication rate at diagnosis [142], results are similar to other populations [144].

The prevalence of arterial hypertension and dyslipidemia is also much higher than in type 1 diabetic patients who have had the disease for the same period of time; a multicentric study conducted in the United States observed that arterial hypertension was present in 10$32 \%$ of young patients with T2D, and it is eight times more frequent than in T1D individuals of the same age [60]. Isolated or combined lipid changes were present in $24-44 \%$ of the cases, albeit only $1 \%$ of those children

Table 6 Chronic complication prevalence among type 1 and type 2 diabetes mellitus in children and adolescents

\begin{tabular}{llll}
\hline & T1D (\%) & T2D (\%) & p \\
\hline Microalbuminuria & 6 & 28 & $<0.001$ \\
Arterial hypertension & 16 & 36 & $<0.001$ \\
Retinopathy & 20 & 4 & 0.43 \\
Peripheral neuropathy & 27 & 21 & 0.48 \\
Obesity & 7 & 56 & $<0.001$ \\
\hline
\end{tabular}

T1D: type 1 diabetes; T2D: type 2 diabetes. Adapted from Eppens, MC et al [142]. were undergoing pharmacological treatment with dyslipidemia [144].

Microalbuminuria is another important risk factor associated with T2D in children and adolescents, which gets worse over the period of time the patient has the disease [142,145-148]. Microalbuminuria is present in $14-25 \%$ at the moment of diagnosis; its incidence is high during the decade following the diagnosis and is linked to glycemic control. Additionally, microalbuminuria in T2D young individuals prematurely evolves to renal failure. During the follow up of Pima Indians with youth-onset type 2 diabetes mellitus, the incidence of diabetic end-stage renal disease was 5 times higher than compared to those who developed diabetes after the age of 20. Similar data were found in Japan when T2D diagnosis occurs before the age of 30 [149].

Apart from classic complications, the risk of non-alcoholic hepatic steatosis, hepatic cirrhosis and portal hypertension is five times higher in children with metabolic syndrome [150-152]. Neuropsychiatric diseases are also more prevalent in young type 2 diabetic individuals. Levitt-Katz and colleagues [153] have demonstrated that $20 \%$ of those patients had some neuropsychiatric disorder such as depression, attention deficit disorder, hyperactivity, neuropsychomotor development disorder, schizophrenia or bipolar disorder. Sixty three per cent of these patients were making use of antipsychotic drugs, increasing the possibility of weight gain by using such drugs, and the possibility of worsening metabolic control by using atypical antipsychotic drugs $[154,155]$.

In conclusion, T2D in children and adolescents is associated with a high number of comorbidities and to the occurrence of complications, deeply affecting the quality of life of those individuals when they are still young. The proper treatment and especially the prevention must be attentively looked at by everyone involved in caring for children at risk of T2D mellitus.

\section{Acknowledgements}

The authors would like to thank Marilia de Brito Gomes for providing technical help and assistance in the organization of the manuscript.

\section{Author details}

${ }^{1}$ Group of Obesity and Metabolic Syndrome, Endocrinology and Metabolism Service, Hospital das Clínicas da Faculdade de Medicina, São Paulo University (HC-FMUSP). Av. Dr. Enéas de Carvalho Aguiar, 155 - $8^{\circ}$ andar - bloco 3. São Paulo, Brazil. ${ }^{2}$ Arterial Hypertension and Lipids Sector of Hospital Universitário Pedro Ernesto - State University of Rio de Janeiro (UERJ). Rua São Francisco Xavier, 524. Rio de Janeiro, Brazil. ${ }^{3}$ Adolescent Center, Department of Pediatrics, Federal University of Sao Paulo (UNIFESP). Rua Pedro de Toledo, 650, 20 andar. São Paulo, Brazil. ${ }^{4}$ Endocrinology and Metabolism Service of Hospital de Clínicas, Department of Nutrition, Federal University of Paraná (UFPR). Rua General Carneiro, 181. Curitiba, Brazil. ${ }^{5}$ Dante Pazzanese Institute of Cardiology of the São Paulo State Health Department. Av. Dr. Dante Pazzanese, 500. São Paulo, Brazil. '5ervice of Endocrinology, Department of Medicine, Federal University of São Paulo (UNIFESP). Rua Pedro de Toledo, 650, $2^{\circ}$ andar. São Paulo, Brazil. ${ }^{7}$ Group of Diabetes, Endocrinology and Metabolism Service, Hospital das Clínicas da Faculdade de 
Medicina, São Paulo University (HC-FMUSP). Av. Dr. Enéas de Carvalho Aguiar, 155 - $8^{\circ}$ andar - bloco 3. São Paulo, Brazil.

\section{Authors' contributions}

$\mathrm{AH}$ : wrote the section about Pharmacological Treatment; MM and MEM: wrote the section about Metabolic Syndrome Diagnosis in Children and Adolescents, revised the manuscript and made the requested formatting changes; MECM: wrote the section about Atherosclerosis in Young Adults; MF: wrote the section about Nutritional Orientation in Children and Adolescents with Metabolic Syndrome; RR: wrote the section about Physical Activity in Children and Adolescent; MCB and AB: wrote the section about Dyslipidemia; MTZ: wrote the section about Hypertension in Children and Adolescents; MQ and MN: wrote the section about T2D in Children and Adolescents.

All authors read and approved the final manuscript.

\section{Competing interests}

The authors declare that they have no competing interests.

Received: 7 December 2009 Accepted: 18 August 2010

Published: 18 August 2010

\section{References}

1. Halpern A, Mancini MC: Treatment of obesity: an update on anti-obesity medications. Obes Rev 2003, 4:25-42.

2. Weiss R, Dziura J, Burgert TS, et al: Obesity and the metabolic syndrome in children and adolescents. N Engl J Med 2004, 350:2362-2374.

3. Mancini MC: Metabolic Syndrome in children and adolescents - criteria for diagnosis. Diabetol Metab Syndr 2009, 1(1):20.

4. Freedman DS, Serdula MK, Srinivasan SR, Berenson GS: Relation of circumferences and skinfold thicknesses to lipid and insulin concentrations in children and adolescents: the Bogalusa Heart Study. Am J Clin Nutr 1999, 69:308-317.

5. Conde WL, Monteiro CA: Body mass index cutoff points for evaluation of nutritional status in Brazilian children and adolescents. J Pediatr 2006, 82:266-272.

6. BMI for Children and Teens:[http://www.cdc.gov/healthyweight/assessing/ bmi/childrens_bmi/about_childrens_bmi.html].

7. Cook S, Weitzman M, Auinger $P$, et al: Prevalence of a metabolic syndrome phenotype in adolescents: Findings from NHANES-III, 19881994. Arch Pediatr Adolesc Med 2003, 157:821-827.

8. Dietschy JM, Turley SD, Spady DK: Role of liver in the mintenance of cholesterol and low density lipoproteins homeostasis in different animal species, including humans. J Lipid Res 1993, 34:1637-1659.

9. Wattigney WA, Weber LS, Srinivasan SR, Berenson GS: The emergency of clinically abnormal levels of cardiovascular disease risk factor variables among young adults: the Bogalusa Heart Study. Prev Med 1995, 24:617-626.

10. Berenson GS, Srinivasan SR, Bao W, Newman WP III, Tracy RE, Wattigney WA: Association between multiple cardiovascular risk factors and atherosclerosis in children and young adults: The Bogalusa Heart Study. New Engl J Med 1998, 338:1650-1656.

11. Mahan CA, Gill HC, Gidding SS, Malcom GT, Newman WP, Tracy RE, Strong JP: PDAY risk score predicts advanced coronary artery atherosclerosis in middle-aged persons as well as youth. Atherosclerosis 2007, 190(2):370-377.

12. Fonseca FL, Brandão AA, Pozzan R, Campana EMG, Pizzi OL Magalhães MEC: A Relação entre a pressão arterial e índices antropométricos na infância/adolescência e o comportamento das variáveis de risco cardiovascular na fase adulta jovem, em seguimento de 17 anos: Estudo do Rio de Janeiro. Rev SOCERJ 2008, 21(5):281-290.

13. Morrison JA, Sprecher DL, Barton BA, Waclawiw MA, Daniels SR: Overweight fat patterning and cardiovascular disease risk factors in black and white girls: The National Heart, Lung and Blood Institute Growth and Health Study. J Pediatr 1999, 135:458-464.

14. Dzau VJ, Antman EM, Black HR, Hayes DL, Manson JE, Plutzky J, Popma JJ, Stevenson W: The cardiovascular disease continuum validated: clinical evidence of improved patient outcomes: Part I: Pathophysiology and clinical trial evidence (risk factors through stable coronary artery disease). Circulation 2006, 114(25):2850-2870.
15. Miura K, Daviglus ML, Dyer AR: Relationship of blood pressure to 25-yea mortality due to coronary heart disease, and all causes in young adult men. Arch Intern Med 2001, 161:1501-1508.

16. McCarron P, Smith GD, Okasha M, McEwen J: Blood pressure in young adulthood and mortality from cardiovascular disease. Lancet 2000, 355:1430-1431

17. Bueno MB, Marchioni DM, Fisberg RM: Changes in the nutritional status of children in public day care facilities in the municipality of São Paulo, Brazil. Rev Panam Salud Publica 2003, 14(3):165-170.

18. Bernardi JR, Cezaro CD, Fisberg RM, Fisberg M, Vitolo MR: Estimation of energy and macronutrient intake at home and in the kindergarten programs in preschool children. J Pediatr (Rio J) 2010, 86(1):59-64.

19. Costa RF, Cintra Ide P, Fisberg M: Prevalence of overweight and obesity in school children of Santos City, Brazil. Ara Bras Endocrinol Metabol 2006, 50(1):60-67.

20. Shetty P: Community-based approaches to address childhood undernutrition and obesity in developing countries. Nestle Nutr Workshop Ser Pediatr Program 2009, 63:227-257.

21. Figueiredo IC, Jaime PC, Monteiro CA: Factors associated with fruit and vegetable intake among adults of the city of São Paulo, Southeastern Brazil. Rev Saude Publica 2008, 42(5):777-785.

22. Srinath RK, Katan MB: Diet, nutrition and the prevention of hypertension and cardiovascular diseases. Public Health Nutr 2004, 7(1A):167-186.

23. Ball GD, Lenk JM, Barbarich BN, Plotnikoff RC, Fishburne GJ, Mackenzie KA, Willows ND: Overweight children and adolescents referred for weight management: are they meeting lifestyle behaviour recommendations? Appl Physiol Nutr Metab 2008, 33(5):936-945.

24. Zemel MB, Donnelly JE, Smith BK, Sullivan DK, Richards J, Morgan-Hanusa D, Mayo MS, Sun X, Cook-Wiens G, Bailey BW, Van Walleghen EL,

Washburn RA: Effects of dairy intake on weight maintenance. Nutr Metab (Lond) 2008, 24(5):28

25. AMA Expert Committee - Appendix: Expert Committee Recommendations on the Assessment, Prevention, and Treatment of Child and Adolescent Overweight and Obesity. [http://www.ama-assn.org/ama1/pub/upload/ $\mathrm{mm} / 433 /$ ped_obesity_recs.pdf]

26. Obarzanek E, Schreiber GB, Crawford PB, et al: Energy intake and physical activity in relation to indexes of body fat: the National Heart, Lung, and Blood Institute Growth and Health Study. Am J Clin Nutr 1994, 60:15-22.

27. Hills AP: Youngsters: Lessons for Childhood Obesity. J Exerc Sci Fit 2009, 7(2):S28-S33.

28. Fox KA, Hillsdon M: Physical activity and obesity. Obes Rev 2007, 8(Suppl.1):115-121

29. Proctor $\mathrm{MH}$, Moore $\mathrm{LL}$, Gao D, et al: Television viewing and change in body fat from preschool to early adolescence: The Framingham Children's Study. Int J Obes 2003, 27:827-833.

30. Almeida SS, Nascimento PC, Quaioti TCB: Amount and quality of food advertisement on Brazilian television. Rev Saude Publica 2002, 36(3):353-355

31. Butte NF, Puyau MR, Adolph AL, Vohra FA, Zakeri I: Physical activity in non overweight and overweight Hispanic children and adolescents. Med Sci Sports Exer 2007, 39:1257-1266.

32. Goran Ml, Gower BA, Nagy TR, Johonson RK: Developmental changes in energy expenditure and physical activity in children: evidence for a decline in physical activity in girls before puberty. Pediatrics 1998 101:887-891.

33. Froberg $K$, Andersen LB: Mini review: Physical activity and fitness and its relations to cardiovascular disease risk factors in children. Int J Obes (Lond) 2005, 29:S34-S39.

34. Eisenmann JC: Aerobic fitness, fatness and the metabolic syndrome in children and adolescents. Acta Paed 2007, 96:1723-1729.

35. Atlantis $E$, Barner EH, Fiatarone SMA: Efficacy of exercise for treating overweight in children and adolescents: a systematic review. Int J Obesity 2006, 30:1027-1040.

36. Caranti DA, Mello MT, Prado WL, et al: Short- and long-term beneficial effects of a multidisciplinary therapy for the control of metabolic syndrome in obese adolescents. Metabolism 2007, 56(9):1293-1300.

37. Leite N, Milano GE, Cieslak F, Lopes WA, Rodacki A, Radominski RB: Effects of physical exercise and nutrition guidance on metabolic syndrome in obese adolescents. Rev Bras Fisiot (Sao Carlos) 2009, 13(1):73-81. 
38. Després JP, Lamarche B: Effects of diet and physical activity on adiposity and body fat distribution: Implications for the prevention of cardiovascular disease. Nutr Res Rev 1993, 6:137-159.

39. Woo KS, Chook P, Yu CW: Effects of diet and exercise on obesity-related vascular dysfunction in children. Circulation 2004, 109(16):1981-1986.

40. Martins C, Morgan L, Truby H: A review of the effects of exercise on appetite regulation: an obesity perspective. Int J Obes 2008, 32:1337-1347

41. Baumer JH: Guideline review - Obesity and overweight: its prevention, identification, assessment and management. Arch Dis Child Educ Pract 2007, 92:92-96.

42. Strong WB, Malina RM, Bumke JR, et al: Evidence based physical activity for school-age youth. J Pediatr 2005, 146:732-737.

43. Andersen $L B$, Harro $M$, Sardinha $L B$, et al: Physical activity and clustered cardiovascular risk in children: a cross sectional study - The European Youth Heart Study. Lancet 2006, 368:299-304.

44. Nowicka P, Flodmark CE: Physical activity- key issues in treatment of childhood obesity. Acta Paed 2006, 96:39-45.

45. Eliakim A, Kaven G, Berger I, et al: The effect of a combined intervention on body mass index and fitness in obese children and adolescents - a clinical experience. Eur J Pediatr 2002, 161:449-454.

46. Malina RM, Bouchard C: Strength and motor performance during growth. In Growth, Maturation, and Physical Activity. Edited by: Malina RM, Bouchard C. Champaign, IL: Human Kinetcs Publishers; 1991:187-204.

47. McWhorter JW, Wallmann HW, Alpert PT: The obese child: Motivation as a toll for exercise. J Pediatr Health Care 2003, 17:11-17.

48. Robbins $L B$, Pender NJ, Kazanis AS: Barriers to physical activity perceived by adolescent girls. J Midwifery Womens Health 2003, 48:206-212.

49. Daniels SR, Jacobson MS, McCrindle BW, et al: American Heart Association Childhood Obesity Research Summit Report. Circulation 2009, 119 e489-e517.

50. Halpern A, Mancini MC: Treatment of obesity - an update on anti-obesity medications. Obes. Rev 2003, 4:25-42.

51. Lean MEJ: Sibutramine, a review of clinical efficacy. Int J Obes Relat Metab Disord 1997, 21(Suppl 1):S30-S36.

52. McDuffie J, Calis K, Uwaifo G, et al: Three-month tolerability of orlistat in adolescents with obesity-related co-morbid conditions. Obes Res 2002, 10:642-650.

53. Wilding J, Van Gaal L, Rissanen A, Vercruysse F, Fitchet M: A randomized double-blind placebo-controlled study of the long-term efficacy and safety of topiramate in the treatment of obese subjects. Int J Obes 2004, 28:1399-1410.

54. Anderson JW, Greenway FL, Fukioka, et al: Bupropion SR enhances weight loss: a 48-week double-blind, placebo-controlled trial. Obes Res 2002, 10:663-641.

55. Goldstein DJ, Rampey AH Jr, Enas GG, Potvin JH, Fludzinski LA, Levine LR: Fluoxetine: a randomized clinical trial in the treatment of obesity. Int J Obes Relat Metab Disord 1994, 18(3):129-35.

56. Kay JP, Alemzadeh R, Langley $G$, et al: Beneficial effects of metformin in normoglycemic morbidly obese adolescents. Metabolism 2001, 50:1457-1461.

57. Freemark M, Bursey D: The effects of metformin on body mass index and glucose tolerance in obese adolescents with fasting hyperinsulinemia and a family history of type 2 diabetes [abstract]. Pediatrics 2001, 107:E55.

58. Srinivasan $S$, Ambler GR, Baur LA, Garnett SP, et al: Randomized, controlled trial of metformin for obesity and insulin resistance in children and adolescents: improvement in body composition and fasting insulin. $J$ Clin Endocrinol Metab 2006, 91(6):2074-2080.

59. Chanoine JP, Hampl S, Jensen C, Boldrin M, Hauptman J: Effect of orlistat on weight and body composition in obese adolescents: a randomized controlled trial. J A M A 2005, 293(23):2873-2883.

60. Godoy-Matos A, Carraro L, Vieira A, et al: Treatment of obese adolescents with sibutramine: a randomized, double-blind, controlled study. J Clin Endocrinol Metab 2005, 90(3):1460-1465.

61. Berkowitz R, Wadden T, Tershakovec A, et al: Behavior therapy and sibutramine for the treatment of adolescent obesity: a randomized controlled trial. J A M A 2003, 289(14):1805-1812.

62. Zimmet $P$, Alberti KG, Kaufman F, et al: The metabolic syndrome in children and adolescents - an IDF consensus report. Pediatr Diabetes 2007, 8(5):299-306.
63. Huijgen R, Vissers MN, Defesche JC, Lansberg PJ, Kastelein JJ, Hutten BA: Familial hypercholesterolemia: current treatment and advances in management. Expert Rev Cardiovasc Ther 2008, 6(4):567-581.

64. Steinberger J, Daniels SR, Eckel RH, et al: Progress and challenges in metabolic syndrome in children and adolescents: a scientific statement from the American Heart Association Atherosclerosis, Hypertension, and Obesity in the Young Committee of the Council on Cardiovascular Disease in the Young; Council on Cardiovascular Nursing; and Council on Nutrition, Physical Activity, and Metabolism. Circulation 2009, 119(4):628-647.

65. Kolansky DM, Cuchel M, Clark BJ, et al: Longitudinal evaluation and assessment of cardiovascular disease in patients with homozygous familial hypercholesterolemia. Am J Cardiol 2008, 102(11):1438-1443.

66. Morrison JA, Friedman LA, Gray-McGuire C: Metabolic syndrome in childhood predicts adult cardiovascular disease 25 years later: the Princeton Lipid Research Clinics Follow-up Study. Pediatrics 2007, 120(2):340-345.

67. Back Gl, Caramelli B, Pellanda L, Duncan B, Mattos S, Fonseca FH: I Guidelines of Prevention of Atherosclerosis in Childhood and Adolescence. Arq Bras Cardiol 2005, 85(Suppl 6):4-36.

68. Daniels SR, Greer FR: Lipid screening and cardiovascular health in childhood. Pediatrics 2008, 122(1):198-208.

69. de Ferranti S, Ludwig DS: Storm over statins - the controversy surrounding pharmacologic treatment of children. N Engl J Med 2008, 359(13):1309-1312.

70. Soutar AK, Naoumova RP: Mechanisms of disease: genetic causes of familial hypercholesterolemia. Nat Clin Pract Cardiovasc Med 2007, 4(4):214-225

71. Cohen JC, Boerwinkle E, Mosley TH Jr, Hobbs HH: Sequence variations in PCSK9, low LDL, and protection against coronary heart disease. $N$ Engl J Med 2006, 354(12):1264-1272.

72. Brown MS, Goldstein JL: Biomedicine. Lowering LDL - not only how low, but how long? Science 2006, 311(5768):1721-1723.

73. Girardet JP: Anticholesteremic agents in children. Therapie 2003, 58(1):63-67.

74. Turley SD: Cholesterol metabolism and therapeutic targets: rationale for targeting multiple metabolic pathways. Clin Cardiol 2004, 27(6 Suppl 3): |||16-||121.

75. Arambepola C, Farmer AJ, Perera R, Neil HA: Statin treatment for children and adolescents with heterozygous familial hypercholesterolaemia: a systematic review and meta-analysis. Atherosclerosis 2007, 195(2):339-347.

76. Gotto AM: Efficacy and safety of statin therapy in children with familial hypercholesterolemia: a randomized controlled trial. J Pediatr 2005, 146(1):144-145.

77. Rodenburg J, Vissers MN, Trip MD, Wiegman A, Bakker HD, Kastelein JJ: The spectrum of statin therapy in hyperlipidemic children. Semin Vasc Med 2004, 4(4):313-320.

78. Rodenburg J, Vissers MN, Wiegman A, et al: Statin treatment in children with familial hypercholesterolemia: the younger, the better. Circulation 2007, 116(6):664-668.

79. Ferreira WP, Bertolami MC, Santos SN, et al: One-month therapy with simvastatin restores endothelial function in hypercholesterolemic children and adolescents. Pediatr Cardiol 2007, 28(1):8-13.

80. MacMahon SW, Blacket RB, Macdonald GJ, Hall W: Obesity, alcohol consumption and blood pressure in Australian men and women - The National Heart Foundation of Australia Risk Factor Prevalence Study. J Hypertens 1984, 2(1):85-91.

81. Hall JE: The kidney, hypertension, and obesity. Hypertension 2003, 41:625-633.

82. Ailhaud G, Fukamizu A, Massiera F, Negrel R, Saint-Marc P, Teboul M: Angiotensinogen, angiotensin II and adipose tissue development. Int J Obes Relat Metab Disord 2000, 24:S33-S35.

83. Dusserre $E$, Moulin $P$, Vidal H: Differences in mRNA expression of the proteins secreted by the adipocytes in human subcutaneous and visceral adipose tissues. Biochim Biophys Acta 2000, 1500:88-96.

84. Hall JE, Hildebrandt DA, Kuo J: Obesity hypertension: role of leptin and sympathetic nervous system. Am J Hypertens 2001, 14:103S-115S.

85. National High Blood Pressure Education Program Working Group on High Blood Pressure in Children and Adolescents: The fourth report on the 
diagnosis, evaluation and treatment of high blood pressure in children and adolescents. Pedriatics 2004, 114:555-576.

86. Brandão AA, Pozzan R, Albanesi Fo FM, Brandão AP: Role of anthropometric indexes and blood pressure as determinants of left ventricular mass and geometry in adolescents: The Rio de Janeiro Study. Hypertension 1995, 26:1190-1194.

87. Hayman LL, Wiliams CL, Daniels SR, Steinberg J, Paridon S, Dennison BA: Cardiovascular health promotion in the schools. Circulation 2004, 110:2266-2275.

88. Shahinfar S, Rippley R, Hogg RJ, et al: Multicenter study of enalapril pharmacokinetics in hypertensive children and infants [abstract]. Pediatr Res 2000, 47:473A.

89. Menon S, Berezny KY, Kilaru R, Benjamin DK Jr, Kay JD, Hazan L, Portman R, Hogg R, Deitchman D, Califf RM, Li JS: Racial differences are seen in blood pressure response to fosinopril in hypertensive children. Am Heart J 2006, 152(2):394-399

90. Soffer B, Zhang Z, Miller K, Vogt BA, Shahinfar SA: Double-blind, placebocontrolled, dose-response study of the effectiveness and safety of lisinopril for children with hypertension. Am J Hypertens 2003, 16(10):795-800.

91. Scheen AJ: Similar reduction in new cases of type 2 diabetes with angiotensin receptor blocker and ACE inhibitor: comparison of metaanalyses of prospective randomised trials. Rev Med Liege 2005, 60(56):424-428.

92. Batisky DL, Sorof JM, Sugg J, Llewellyn M, Klibaner M, Hainer JW, Portman RJ, Falkner B: Efficacy and safety of extended release metoprolol succinate in hypertensive children 6 to 16 years of age: a clinical trial experience. Pediatr 2007, 150(2):134-139.

93. Bangalore S, Parkar S, Grossman E, Messerli FHA: A meta-analysis of 94,492 patients with hypertension treated with beta blockers to determine the risk of new-onset diabetes mellitus. Am J Cardiol 2007, 100(8):1254-62.

94. Libman I, Arslanian SA: Type II diabetes mellitus: no longer just adults. Pediatr Ann 1999, 28:589-593.

95. Liese AD, D'Agostino RB Jr, Hamman RF, Kilgo PD, Lawrence JM, Liu LL, Loots B, Linder B, Marcovina S, Rodriguez B, Standiford D, Williams DE: The burden of diabetes mellitus among US youth: prevalence estimates from the SEARCH for Diabetes in Youth Study. Pediatrics 2006, 118:1510-1518.

96. Ehtisham S, Hattersley AT, Dunger DB, Barrett TG: First UK survey of paediatric type 2 diabetes and MODY. Arch Dis Child 2004, 89:526-529.

97. Ortega-Rodriguez E, Levy-Marchal C, Tubiana N, Czernichow P, Polak M: Emergence of type 2 diabetes in an hospital based cohort of children with diabetes mellitus. Diabetes Metab 2001, 27:574-578

98. Rami B, Schober E, Nachbauer E, Waldhor T: Type 2 diabetes mellitus is rare but not absent in children under 15 years of age in Austria. Eur J Pediatr 2003, 162:850-852.

99. Schober E, Holl RW, Grabert M, Thon A, Rami B, Kapellen T, Seewi O, Reinehr T: Diabetes mellitus type 2 in childhood and adolescence in Germany and parts of Austria. Eur J Pediatr 2005, 164:705-707.

100. Herder C, Schmitz-Beuting C, Rathmann W, Haastert B, Schmitz-Beuting J, Schafer M, Scherbaum WA, Schneitler H, Martin S: Prevalence of impaired glucose regulation in German school-leaving students. Int I Obes (Lond) 2007, 31:1086-1088.

101. Mazza CS, Ozuna B, Krochik AG, Araujo MB: Prevalence of type 2 diabetes mellitus and impaired glucose tolerance in obese Argentinean children and adolescents. J Pediatr Endocrinol Metab 2005, 18:491-498.

102. Kitagawa T, Owada M, Urakami T, Yamauchi K: Increased incidence of noninsulin dependent diabetes mellitus among Japanese schoolchildren correlates with an increased intake of animal protein and fat. Clin Pediatr (Phila) 1998, 37:111-115.

103. Silva ARV, Damasceno MMC, Carvalho ZMdF, Hissa MN, Almeida PC, Silva LF: Prevalencia de factores de riesgo para diabetes mellitus tipo 2 en adolescentes de Fortaleza - Brasil. Enfermería Integral 2007, 7:11-14.

104. Carneiro IRI, Kushnir MC, Clemente ES, Brandão MG, Gomes MB: Obesidade na adolescência: fator de risco para complicações clínico-metabolicas. Ara Bras Endocrinol Metab 2000, 44:390-396.

105. Gungor N, Bacha F, Saad R, Janosky J, Arslanian S: Youth type 2 diabetes: insulin resistance, beta-cell failure, or both? Diabetes Care 2005, 28:638-644.

106. Saad R, Gungor N, Arslanian S: Progression from normal glucose tolerance to type 2 diabetes in a young girl: longitudinal changes in insulin sensitivity and secretion assessed by the clamp technique and surrogate estimates. Pediatr Diabetes 2005, 6:95-99.

107. Gungor N, Arslanian S: Progressive beta cell failure in type 2 diabetes mellitus of youth. J Pediatr 2004, 144:656-659.

108. Matthews DR, Cull CA, Stratton IM, Holman RR, Turner RC: UKPDS 26: Sulphonylurea failure in non-insulin-dependent diabetic patients over six years. UK Prospective Diabetes Study (UKPDS) Group. Diabet Med 1998, 15:297-303.

109. Miller J: Type 2 diabetes in child and adolescent. In Pediatric Endocrinology. Edited by: Lifshitz F. Marcel Dekker: New York; 2007:169-188.

110. Klein BE, Klein R, Moss SE, Cruickshanks KJ: Parental history of diabetes in a population-based study. Diabetes Care 1996, 19:827-830.

111. Boney CM, Verma A, Tucker R, Vohr BR: Metabolic syndrome in childhood: association with birth weight, maternal obesity, and gestational diabetes mellitus. Pediatrics 2005, 115:e290-e296.

112. McCance DR, Pettitt DJ, Hanson RL, Jacobsson LT, Knowler WC, Bennett PH: Birth weight and non-insulin dependent diabetes: thrifty genotype, thrifty phenotype, or surviving small baby genotype? BMJ 1994, 308:942-945.

113. Carter JS, Pugh JA, Monterrosa A: Non-insulin-dependent diabetes mellitus in minorities in the United States. Ann Intern Med 1996, 125:221-232.

114. Astrup A, Dyerberg J, Selleck M, Stender S: Nutrition transition and its relationship to the development of obesity and related chronic diseases. Obes Rev 2008, 9(Suppl 1):48-52.

115. Legro RS, Gnatuk CL, Kunselman AR, Dunaif A: Changes in glucose tolerance over time in women with polycystic ovary syndrome: a controlled study. J Clin Endocrinol Metab 2005, 90:3236-3242.

116. Palmert MR, Gordon CM, Kartashov Al, Legro RS, Emans SJ, Dunaif A: Screening for abnormal glucose tolerance in adolescents with polycystic ovary syndrome. J Clin Endocrinol Metab 2002, 87:1017-1023.

117. Brickman WJ, Holland JS, Silverman BL: Prevalence of postprandial hyperglycemia in adolescents: a population-based study. Diabetes Care 2002, 25:1887-1888.

118. Weiss R, Dufour S, Taksali SE, Tamborlane WW, Petersen KF, Bonadonna RC, Boselli L, Barbetta G, Allen K, Rife F, Savoye M, Dziura J, Sherwin R, Shulman Gl, Caprio S: Prediabetes in obese youth: a syndrome of impaired glucose tolerance, severe insulin resistance, and altered myocellular and abdominal fat partitioning. Lancet 2003, 362:951-957.

119. Rosenbloom AL, Silverstein $\mathrm{JH}$, Amemiya S, Zeitler $P$, Klingensmith GJ: ISPAD Clinical Practice Consensus Guideline 2006-2007. Type 2 diabetes mellitus in the child and adolescent. Pediatr Diabetes 2008, 9:512-526.

120. Amiel SA, Sherwin RS, Simonson DC, Lauritano AA, Tamborlane WV: Impaired insulin action in puberty. A contributing factor to poor glycemic control in adolescents with diabetes. N Engl J Med 1986, 315:215-219.

121. Ball GD, Huang TT, Gower BA, Cruz ML, Shaibi GQ, Weigensberg MJ, Goran MI: Longitudinal changes in insulin sensitivity, insulin secretion, and beta-cell function during puberty. J Pediatr 2006, 148:16-22.

122. Expert Committee on the Diagnosis and Classification of Diabetes Mellitus: Report of the Expert Committee on the Diagnosis and Classification of Diabetes Mellitus. Diabetes Care 1997, 20:1183-1197.

123. Libman IM, Arslanian SA: Prevention and treatment of type 2 diabetes in youth. Horm Res 2007, 67:22-34.

124. Hannon TS, Rao G, Arslanian SA: Childhood obesity and type 2 diabetes mellitus. Pediatrics 2005, 116:473-480.

125. Invitti C, Guzzaloni G, Gilardini L, Morabito F, Viberti G: Prevalence and concomitants of glucose intolerance in European obese children and adolescents. Diabetes Care 2003, 26:118-124.

126. Wiegand S, Maikowski U, Blankenstein O, Biebermann H, Tarnow $P$, Gruters A: Type 2 diabetes and impaired glucose tolerance in European children and adolescents with obesity - a problem that is no longer restricted to minority groups. Eur J Endocrinol 2004, 151:199-206.

127. Rosenbloom AL: Hyperglycemic crises and their complications in children. J Pediatr Endocrinol Metab 2007, 20:5-18.

128. Bhowmick SK, Levens KL, Rettig KR: Hyperosmolar hyperglycemic crisis: an acute life-threatening event in children and adolescents with type 2 diabetes mellitus. Endocr Pract 2005, 11:23-29.

129. Carchman RM, Dechert-Zeger M, Calikoglu AS, Harris BD: A new challenge in pediatric obesity: pediatric hyperglycemic hyperosmolar syndrome. Pediatr Crit Care Med 2005, 6:20-24. 
130. Cochran JB, Walters S, Losek JD: Pediatric hyperglycemic hyperosmolar syndrome: diagnostic difficulties and high mortality rate. Am J Emerg Med 2006, 24:297-301.

131. Sapru A, Gitelman SE, Bhatia S, Dubin RF, Newman TB, Flori H: Prevalence and characteristics of type 2 diabetes mellitus in 9-18 year-old children with diabetic ketoacidosis. J Pediatr Endocrinol Metab 2005, 18:865-872.

132. Matyka KA: Type 2 diabetes in childhood: epidemiological and clinical aspects. Br Med Bull 2008, 86:59-75

133. Rodbard HW, Blonde L, Braithwaite SS, Brett EM, Cobin RH, Handelsman Y, Hellman R, Jellinger PS, Jovanovic LG, Levy P, Mechanick Jl, Zangeneh F: American Association of Clinical Endocrinologists medical guidelines for clinical practice for the management of diabetes mellitus. Endocr Pract 2007, 13(Suppl 1):1-68.

134. Harwood K, Vuguin P, DiMartino-Nardi J: Current approaches to the diagnosis and treatment of polycystic ovarian syndrome in youth. Horm Res 2007, 68:209-217.

135. Jones KL, Arslanian S, Peterokova VA, Park JS, Tomlinson MJ: Effect of metformin in pediatric patients with type 2 diabetes: a randomized controlled trial. Diabetes Care 2002, 25:89-94.

136. Glaser B, Cerasi E: Early intensive insulin treatment for induction of longterm glycaemic control in type 2 diabetes. Diabetes Obes Metab 1999, 1:67-74.

137. Sellers EA, Dean HJ: Short-term insulin therapy in adolescents with type 2 diabetes mellitus. J Pediatr Endocrinol Metab 2004, 17:1561-1564.

138. Ryan EA, Imes S, Wallace C: Short-term intensive insulin therapy in newly diagnosed type 2 diabetes. Diabetes Care 2004, 27:1028-1032.

139. Nathan DM: Glycemic management of type 2 diabetes: how tight is right and how to get there. Arch Intern Med 2008, 168:2064-2066.

140. U.K. Prospective Diabetes Study Group: U.K. prospective diabetes study 16. Overview of 6 years' therapy of type II diabetes: a progressive disease. Diabetes 1995, 44:1249-1258.

141. Bagust A, Beale S: Deteriorating beta-cell function in type 2 diabetes: a long-term model. QJM. 2003, 96(4):281-288.

142. Eppens MC, Craig ME, Cusumano J, Hing S, Chan AK, Howard NJ, Silink M, Donaghue KC: Prevalence of diabetes complications in adolescents with type 2 compared with type 1 diabetes. Diabetes Care 2006, 29:1300-1306.

143. Pinhas-Hamiel O, Zeitler P: Acute and chronic complications of type 2 diabetes mellitus in children and adolescents. Lancet 2007 369:1823-1831.

144. Kershnar AK, Daniels SR, Imperatore G, Palla SL, Petitti DB, Pettitt DJ, Marcovina S, Dolan LM, Hamman RF, Liese AD, Pihoker C, Rodriguez BL: Lipid abnormalities are prevalent in youth with type 1 and type 2 diabetes: the SEARCH for Diabetes in Youth Study. J Pediatr 2006, 149:314-319.

145. Rodriguez BL, Fujimoto WY, Mayer-Davis EJ, Imperatore G, Williams DE, Bell RA, Wadwa RP, Palla SL, Liu LL, Kershnar A, Daniels SR, Linder B: Prevalence of cardiovascular disease risk factors in U.S. children and adolescents with diabetes: the SEARCH for diabetes in youth study. Diabetes Care 2006, 29:1891-1896.

146. Yokoyama H, Okudaira M, Otani T, Takaike H, Miura J, Saeki A, Uchigata Y, Omori Y: Existence of early-onset NIDDM Japanese demonstrating severe diabetic complications. Diabetes Care 1997, 20:844-847.

147. Zdravkovic V, Daneman D, Hamilton J: Presentation and course of Type 2 diabetes in youth in a large multi-ethnic city. Diabet Med 2004, 21:1144-1148.

148. Maahs DM, Snively BM, Bell RA, Dolan L, Hirsch I, Imperatore G, Linder B, Marcovina SM, Mayer-Davis EJ, Pettitt DJ, Rodriguez BL, Dabelea D: Higher prevalence of elevated albumin excretion in youth with type 2 than type 1 diabetes: the SEARCH for Diabetes in Youth study. Diabetes Care 2007, 30:2593-2598.

149. Pavkov ME, Bennett PH, Knowler WC, Krakoff J, Sievers ML, Nelson RG: Effect of youth-onset type 2 diabetes mellitus on incidence of end-stage renal disease and mortality in young and middle-aged Pima Indians. J A M A 2006, 296:421-426.

150. McGavock J, Sellers E, Dean H: Physical activity for the prevention and management of youth-onset type 2 diabetes mellitus: focus on cardiovascular complications. Diab Vasc Dis Res 2007, 4:305-310.

151. Nadeau K, Klingensmith G, Zeitler P: Type 2 diabetes in children is frequently associated with elevated alanine aminotransferase. J Pediatr Gastroenterol Nutr 2005, 41:94-98.
152. Schwimmer JB, Pardee PE, Lavine JE, Blumkin AK, Cook S: Cardiovascular risk factors and the metabolic syndrome in pediatric nonalcoholic fatty liver disease. Circulation 2008, 118:277-283.

153. Levitt Katz LE, Swami S, Abraham M, Murphy KM, Jawad AF, McKnightMenci $H$, Berkowitz R: Neuropsychiatric disorders at the presentation of type 2 diabetes mellitus in children. Pediatr Diabetes 2005, 6:84-89.

154. Reis JS, Alvarenga T, Rosario PW, Menezes PA, Rocha RS, Purisch S: Diabetes mellitus associated with atypical antipsychotic medications: case report and review of the literature. Ara Bras Endocrinol Metabol 2007, 51:488-493.

155. Buchholz S, Morrow AF, Coleman PL: Atypical antipsychotic-induced diabetes mellitus: an update on epidemiology and postulated mechanisms. Intern Med J 2008, 38:602-606.

doi:10.1186/1758-5996-2-55

Cite this article as: Halpern et al:: Metabolic syndrome, dyslipidemia, hypertension and type 2 diabetes in youth: from diagnosis to treatment. Diabetology \& Metabolic Syndrome 2010 2:55.

\section{Submit your next manuscript to BioMed Central and take full advantage of:}

- Convenient online submission

- Thorough peer review

- No space constraints or color figure charges

- Immediate publication on acceptance

- Inclusion in PubMed, CAS, Scopus and Google Scholar

- Research which is freely available for redistribution

Submit your manuscript at www.biomedcentral.com/submit
C Biomed Central 